\title{
Antioxidant Activities of Vaccinium vitis-idaea L. Leaves within Cultivars and Their Phenolic Compounds
}

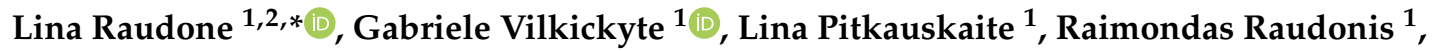 \\ Rimanta Vainoriene ${ }^{3}$ and Vida Motiekaityte ${ }^{4}$ \\ 1 Department of Pharmacognosy, Lithuanian University of Health Sciences, Sukileliu av. 13, LT-50162 Kaunas, \\ Lithuania; gabriele.vilkickyte@fc.lsmuni.lt (G.V.); lina.pitkauskaite@fc.lsmuni.lt (L.P.); \\ raimondas.raudonis@lsmuni.lt (R.R.) \\ 2 Laboratory of Biopharmaceutical Research, Institute of Pharmaceutical Technologies, \\ Lithuanian University of Health Sciences, Sukileliu av. 13, LT-50162 Kaunas, Lithuania \\ 3 The Botanical Garden of Siauliai University, Paitaiciu str. 4, LT-77175 Siauliai, Lithuania; \\ rimanta.vainoriene@su.lt \\ 4 Biomedical Sciences Department, Siauliai State College. Ausros av. 40, LT-76241 Siauliai, Lithuania; \\ vmotiek@gmail.com \\ * Correspondence: lina.raudone@1smuni.lt; Tel.: +37-037-327-249
}

Academic Editors: Susana M. Cardoso and Alessia Fazio Received: 1 February 2019; Accepted: 22 February 2019; Published: 27 February 2019

\begin{abstract}
Lingonberry leaves are the subject of numerous studies because of antioxidant properties, positive influence on the health and potential use in the prevention and treatment of chronic diseases. In this work, the radical scavenging, reducing, chelating activities, and phenolic composition of ten lingonberry leaves cultivars, one subspecies, and one variety were investigated. Furthermore, the antioxidant activity of individual phenolic compounds, that can be found in lingonberry leaves, were analyzed, and structure-activity relationship was determined. Wide diversity for phenolic profile and antioxidant properties of lingonberry leaves has been observed in the present material. Cultivars 'Kostromskaja rozovaja', 'Rubin', and Vaccinium vitis-idaea var. leucocarpum surpassed all others tested cultivars and lower taxa by contents of phenolic compounds and antioxidant activity. Leaves of lingonberry cultivars and lower taxa are rich in arbutin, flavonol glycosides, proanthocyanidins, and the latter were considered to be the major contributor to antioxidant properties of lingonberry leaves.
\end{abstract}

Keywords: lingonberry; Vaccinium vitis-idaea; antioxidant activity; phenolic compounds; HPLC-PDA; structure-activity relationship

\section{Introduction}

Lingonberry (Vaccinium vitis-idaea L.) is an evergreen shrub of the Ericaceae Juss. family. It is one of the most popular berries in Nordic countries, as well as in Baltic States, Russia and Canada [1,2]. Lingonberry raw materials are mainly collected in natural habitats. In Lithuania the area and productivity of the natural populations of lingonberries are declining, as well as they are unevenly distributed [3]. Research on natural resources assessment is relevant because anthropogenic factors have a negative impact on the populations of lingonberry. Sustainable use of natural resources becomes of crucial importance. Cultivation of introduced and locally selected lingonberries could be the best option to provide for the increasing needs of this plant material. Lingonberries are widely used in the human diet due to nutritional benefits, moreover, leaves of this plant can be used for prevention and treatment of urinary tract infections, stomach disorders, rheumatic diseases and hypercholesterolemia [1-5]. The wide spectrum of various biological properties of lingonberry leaves, including antioxidant activity is related to their phenolic constituents $[4,6,7]$. 
It is known that phenolic compounds can transfer an electron or hydrogen atom from the phenolic group to the reactive free radicals, and thus act as reducing agents or free radical scavengers. Also, they are able to form $\sigma$ bonds, and therefore to chelate transition metals, which are powerful pro-oxidants. Because of several mechanisms of action, phenolic compounds ensure the effective defense mechanism against potentially harmful radical species, hence predispose preventing or postponing the onset of various human degenerative and chronic diseases [8-10]. Differences between the predominant mechanism of action and antioxidant properties of phenolic compounds are due to the number and positions of hydroxyl groups, the sugar moiety and other features in the chemical structure. Structural diversity also determines the differences between reactivity and reaction kinetics of phenolic compounds [8,11,12]. For some compounds (i.e., p-coumaric acid, gallic acid, caffeic acid, ferulic acid, (+)-catechin, gallocatechin, catechin gallate, gallocatechin gallate, rutin) there is no or small initial fast reaction and slow continuous reaction afterward [13]. In the online post-column methods, the reaction in the reactor between antioxidant and reagent usually lasts for less than a minute. Consequently, the antioxidant activity of the slow-acting compounds could be evaluated inaccurately. Therefore, antioxidant activities of phenolic compounds, which can be detected in lingonberry leaves, were evaluated by spectrophotometric methods of analysis in the end point of reaction.

Many factors are related to the production of phenolic compounds in plants, among this, there are external factors, such as exposure of the light, solar radiation, temperature, type of soil, cultivation methods, insect attacks, and internal factors-genetic background. These factors especially genetic diversity, cause wide variations even within a single species $[14,15]$. Therefore we have chosen to analyze ten different cultivars, one subspecies and one variety of lingonberries. To the best of our knowledge, the antioxidant activity and phenolic composition of these certain cultivars and lower taxa of lingonberries-'Sussi', 'Erntekrone', 'Masovia', 'Koralle', 'Kostromskaja rozovaja', 'Sanna', 'Rubin', 'Kostromička', 'Erntesegen', 'Erntedank', V. vitis-idaea subsp. minus, and V. vitis-idaea var. leucocarpum have not been compared and determined before.

This study was carried out to determine the radical scavenging, reducing and chelating activities of different cultivars and lower taxa of lingonberry leaves extracts, also to evaluate phenolics composition and major contributors to the antioxidant properties. In addition, the structure-antioxidant activity relationship of phenolic compounds detected in lingonberry leaves were analyzed.

\section{Results}

\subsection{Antioxidant Activity of Lingonberry Leaves Extracts}

\subsubsection{ABTS Radical Scavenging Activity}

The radical scavenging activity of different lingonberry cultivars and lower taxa is shown in Figure 1. The radical scavenging activity ranged from 620.49 to $2179.71 \mathrm{mg} / \mathrm{g}$ dry weight (DW). The average of radical scavenging activity of different cultivars and lower taxa was $1188.04 \mathrm{mg} / \mathrm{g}$ DW. The obtained results clearly showed that the highest radical scavenging activity $(2179.71 \pm 154.88 \mathrm{mg} / \mathrm{g} \mathrm{DW})$ was determined in 'Erntesegen' cultivar-almost two times more than the average. There were no significant differences between 'Erntesegen' and 'Sussi' cultivars. Radical scavenging activity of 'Rubin' and 'Kostromskaja rozovaja' cultivars was a bit lower than average, whereas other antioxidant activity assays demonstrated that these cultivars showed strong antioxidant activity. The lowest radical scavenging activity was found in $V$. vitis-idaea subsp. minus, 'Kostromička', 'Erntekrone', and 'Erntedank' cultivars. 


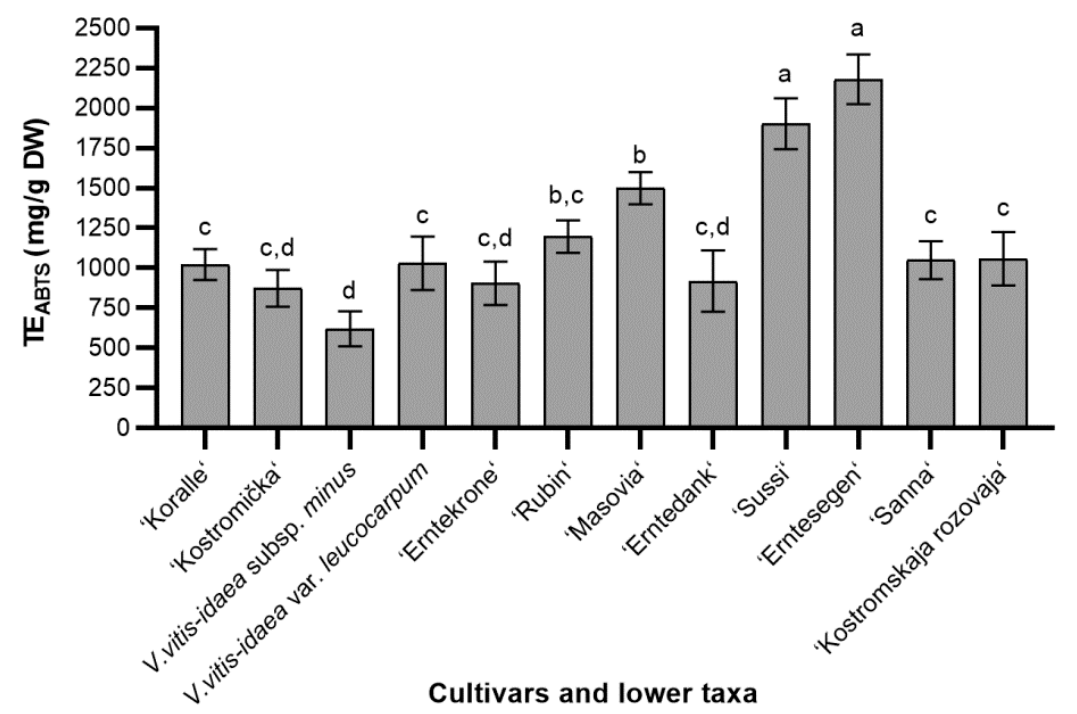

Figure 1. The radical scavenging activity of different cultivars and lower taxa of lingonberry leaves extracts; bars without the same letters $(a, b, c, d)$ indicate statistically significant differences between the means $(p<0.05)$.

\subsubsection{Ferric Reducing Antioxidant Power (FRAP)}

The results provided in Figure 2 demonstrate the reducing activity of the different lingonberry cultivars and lower taxa. The reducing activity among the cultivars and lower taxa studied ranged with values from 743.38 to $1476.04 \mathrm{mg} / \mathrm{g}$ DW. The average of reducing power activity of different cultivars and lower taxa was $1101.32 \mathrm{mg} / \mathrm{g}$ DW. 'Rubin', 'Sussi' and 'Kostromskaja rozovaja' presented the highest reducing power activity and they did not differ significantly. These cultivars demonstrated significantly strong antioxidant activity compared to 'Erntedank' and 'Masovia' cultivars. Higher than average reducing activity was determined in V. vitis-idaea var. leucocarpum and 'Erntesegen' cultivar. Overall, 'Rubin' leaves revealed the greatest antioxidant properties, whereas the 'Erntedank' leaves possessed a very poor antioxidant activity-almost one and a half times lower than average.

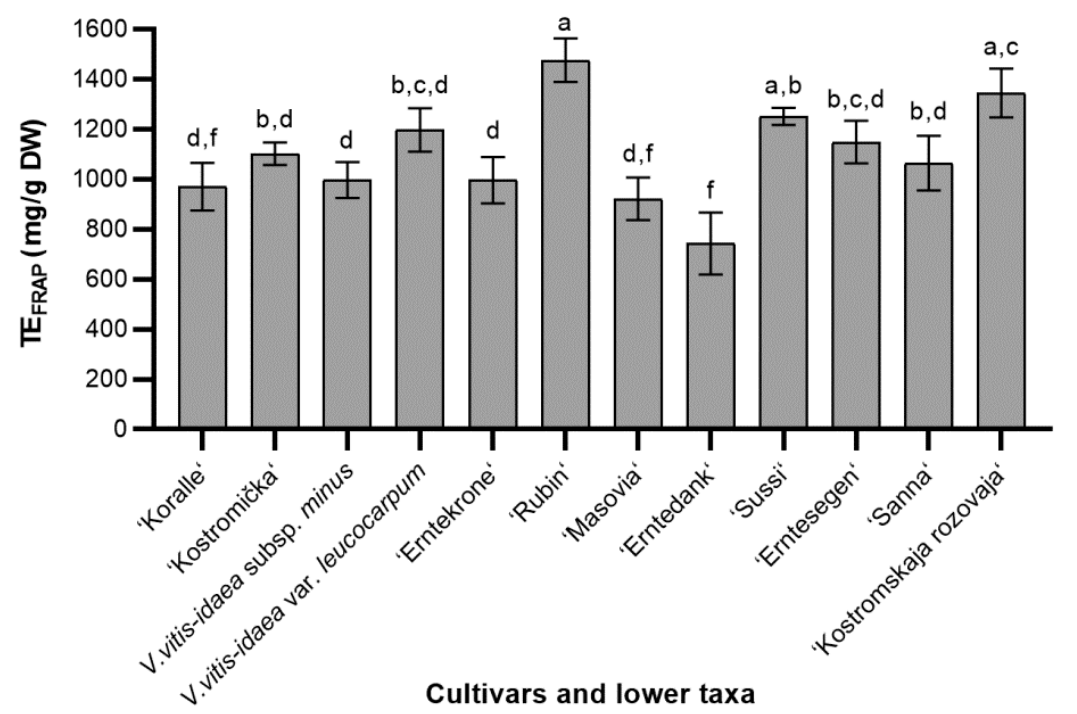

Figure 2. The reducing activity of different cultivars and lower taxa of lingonberry leaves extracts; bars without the same letters $(a, b, c, d, f)$ indicate statistically significant differences between the means $(p<0.05)$. 


\subsubsection{Ferrous Ions Chelating (FIC) Activity}

Chelating activity showed statistically significant variations throughout the different cultivars and lower taxa of lingonberry leave extracts (Figure 3). The ability of extracts to chelate ferrous ions ranged between $34.67 \pm 3.05 \%$ and $79.85 \pm 1.92 \%$. The average of chelating activity of different cultivars and lower taxa of lingonberries was $62.21 \%$. In this study, the highest chelating activity was determined in 'Rubin' cultivar, and it was almost the same as $10 \mu \mathrm{g} / \mathrm{mL}$ of standard chelator-EDTA (data not shown). There were no significant differences between the V. vitis-idaea var. leucocarpum and 'Rubin', 'Sussi', 'Kostromskaja rozovaja' cultivars. Higher than average chelating ability was also established in 'Kostromička', 'Erntesegen', and 'Entekrone' cultivars. This suggests that these cultivars of lingonberries are rich in compounds, which captures ferrous ions before ferrozine. Meanwhile, the lowest chelating activity-almost two times lower than average, was found in 'Koralle' cultivar, and one and a half times lower-in 'Erntedank' cultivar. By comparison with other cultivars, these differences were statistically significant. Obtained results indicate that there is a wide genetic diversity for chelating properties of lingonberry leaves, and chelating activity possibly depends on the phytochemical content of cultivar or lower taxa.

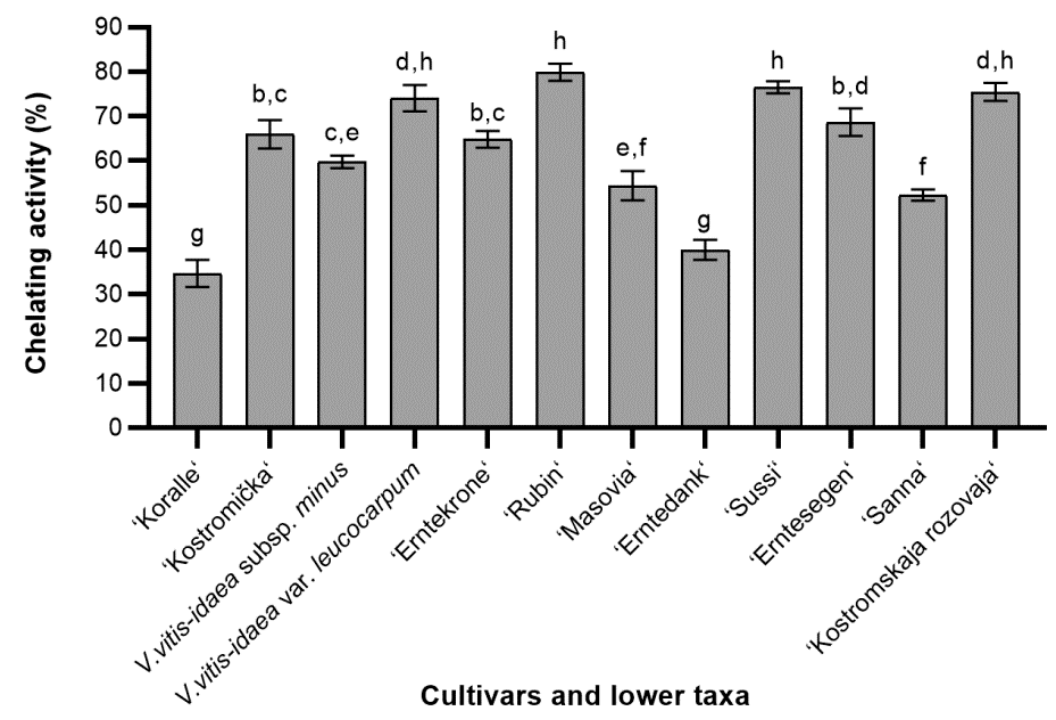

Figure 3. The chelating activity of different cultivars and lower taxa of lingonberry leaves extracts; bars without the same letters $(a, b, c, d, e, f, g, h)$ indicate statistically significant differences between the means $(p<0.05)$.

\subsection{Qualitative and Quantitative Analysis of Phenolic Compounds in Lingonberry Leaves}

The results of high-performance liquid chromatography-photodiode array detection (HPLC-PDA) method of analysis, showed that eleven phenolic compounds, belonging to subgroups of simple phenols, flavonols, flavanols, proanthocyanidins, and hydroxycinnamic acids were detected in different cultivars, and lower taxa of lingonberry leaves extracts (Table 1, Table 2). 
Table 1. Contents of flavonols and simple phenols ( $\mu \mathrm{g} / \mathrm{g} \mathrm{DW})$ of Lingonberry leaves extracts.

\begin{tabular}{cccccc}
\hline \multirow{2}{*}{ Cultivars } & \multicolumn{5}{c}{ Compounds } \\
\cline { 2 - 6 } & Astragalin & Avicularin & Hyperoside & Quercitrin & Arbutin \\
\hline 'Sussi' & $53.22 \pm 2.17 \mathrm{~d}{ }^{1}$ & $1681.92 \pm 68.66 \mathrm{a}$ & $1744.85 \pm 71.23 \mathrm{a}$ & $2686.48 \pm 109.68 \mathrm{a}, \mathrm{b}$ & $16,445.51 \pm 671.39 \mathrm{a}, \mathrm{b}$ \\
\hline 'Erntekrone' & $5.19 \pm 0.21 \mathrm{a}$ & $3479.62 \pm 142.06 \mathrm{e}$ & $4380.64 \pm 178.84 \mathrm{e}$ & $1692.27 \pm 69.09 \mathrm{~d}$ & $12,441.17 \pm 507.91 \mathrm{a}, \mathrm{c}$ \\
\hline 'Masovia' & $3.07 \pm 0.13 \mathrm{a}$ & $2313.59 \pm 94.45 \mathrm{~b}$ & $2522.88 \pm 103.00 \mathrm{~b}$ & $1676.31 \pm 68.43 \mathrm{~d}$ & $20,997.03 \pm 857.20 \mathrm{~b}, \mathrm{~d}$ \\
\hline 'Koralle' & $6.53 \pm 0.27 \mathrm{e}$ & $2261.69 \pm 92.33 \mathrm{~b}, \mathrm{c}$ & $2939.20 \pm 119.99 \mathrm{c}$ & $7826.68 \pm 319.52 \mathrm{f}$ & $13,755.55 \pm 561.57 \mathrm{a}$ \\
\hline V. vitis-idaea subsp. minus & $8.89 \pm 0.36 \mathrm{a}$ & $2419.27 \pm 98.77 \mathrm{~b}, \mathrm{~d}$ & $5771.34 \pm 235.61 \mathrm{~d}$ & $5782.61 \pm 236.07 \mathrm{~g}$ & $28,708.70 \pm 1172.03 \mathrm{e}$ \\
\hline 'Kostromskaja rozovaja' & $114.67 \pm 4.68 \mathrm{~b}, \mathrm{c}$ & $2158.17 \pm 88.11 \mathrm{~b}, \mathrm{c}$ & $2342.03 \pm 95.61 \mathrm{~b}$ & $1871.89 \pm 76.42 \mathrm{~d}, \mathrm{e}$ & $56,968.56 \pm 2325.73 \mathrm{~g}$ \\
\hline 'Sanna' & $4.38 \pm 0.18 \mathrm{a}$ & $2179.45 \pm 88.98 \mathrm{f}$ & $1926.56 \pm 78.65 \mathrm{a}$ & $2632.32 \pm 107.46 \mathrm{a}, \mathrm{b}$ & $7070.25 \pm 288.64 \mathrm{c}$ \\
\hline 'Rubin' & $120.60 \pm 4.92 \mathrm{~b}$ & $3113.46 \pm 127.11 \mathrm{~g}$ & $3084.12 \pm 125.91 \mathrm{c}$ & $2628.62 \pm 107.31 \mathrm{a}, \mathrm{b}$ & $36,059.47 \pm 1472.12 \mathrm{f}$ \\
\hline 'Kostromička' & $108.79 \pm 4.44 \mathrm{c}$ & $2715.82 \pm 110.87 \mathrm{~d}$ & $3520.41 \pm 143.72 \mathrm{f}$ & $2471.29 \pm 100.89 \mathrm{a}, \mathrm{c}$ & $29,877.25 \pm 1219.73 \mathrm{e}, \mathrm{f}$ \\
\hline V. vitis-idaea var. leucocarpum & $82.02 \pm 3.35 \mathrm{f}$ & $5503.44 \pm 224.68 \mathrm{~g}$ & $5682.61 \pm 231.99 \mathrm{~d}$ & $2139.10 \pm 87.33 \mathrm{c}, \mathrm{e}$ & $23,356.78 \pm 953.54 \mathrm{~d}, \mathrm{e}$ \\
\hline 'Erntesegen' & $23.15 \pm 0.95 \mathrm{~g}$ & $1941.79 \pm 79.27 \mathrm{c}$ & $1764.92 \pm 72.05 \mathrm{a}$ & $1723.17 \pm 70.35 \mathrm{~d}, \mathrm{e}$ & $8963.10 \pm 365.92 \mathrm{c}$ \\
\hline 'Erntedank' & $111.77 \pm 4.56 \mathrm{c}$ & $1946.56 \pm 79.47 \mathrm{c}$ & $1561.43 \pm 63.74 \mathrm{a}$ & $2953.06 \pm 120.56 \mathrm{~b}$ & $7443.27 \pm 303.87 \mathrm{c}$ \\
\hline
\end{tabular}

${ }^{1}$ Contents marked without the same letters $(\mathrm{a}, \mathrm{b}, \mathrm{c}, \mathrm{d}, \mathrm{e}, \mathrm{f}, \mathrm{g})$ in the columns indicate statistically significant differences among cultivars or lower taxa $(p<0.05)$.

Table 2. Contents of flavanols, proanthocyanidins, and hydroxycynnamic acids ( $\mu \mathrm{g} / \mathrm{g} \mathrm{DW}$ ) of Lingonberry leaves extracts.

\begin{tabular}{ccccccc}
\hline \multirow{2}{*}{ Cultivars } & \multicolumn{5}{c}{ Compounds } \\
\cline { 2 - 7 } & (+)-Catechin & (-)-Epicatechin & Procyanidin C1 & Procyanidin A2 & Chlorogenic Acid & Cryptochlorogenic Acid \\
\hline 'Sussi' & $897.82 \pm 36.65 \mathrm{a}{ }^{1}$ & $252.14 \pm 10.29 \mathrm{c}$ & $1332.85 \pm 54.41 \mathrm{a}, \mathrm{b}$ & $1040.11 \pm 42.46 \mathrm{a}$ & $346.25 \pm 14.14 \mathrm{a}$ & $417.74 \pm 17.05 \mathrm{~b}$ \\
\hline 'Erntekrone' & $595.09 \pm 24.29 \mathrm{~b}$ & $26.27 \pm 1.07 \mathrm{a}$ & $1071.21 \pm 43.73 \mathrm{a}, \mathrm{c}$ & $3609.57 \pm 147.36 \mathrm{~b}$ & $318.35 \pm 13.00 \mathrm{a}$ & $368.86 \pm 15.06 \mathrm{~b}, \mathrm{c}$ \\
\hline 'Masovia' & $2954.64 \pm 120.62 \mathrm{e}$ & $571.32 \pm 23.32 \mathrm{~d}$ & $1090.83 \pm 44.53 \mathrm{a}, \mathrm{c}$ & $3554.68 \pm 145.12 \mathrm{~b}$ & $532.09 \pm 21.72 \mathrm{~b}$ & $334.89 \pm 13.67 \mathrm{c}$ \\
\hline 'Koralle' & $605.81 \pm 24.73 \mathrm{~b}, \mathrm{c}$ & $71.80 \pm 2.93 \mathrm{~b}$ & $1248.83 \pm 50.98 \mathrm{a}, \mathrm{b}, \mathrm{d}$ & $3003.60 \pm 122.62 \mathrm{c}, \mathrm{d}$ & $189.75 \pm 7.75 \mathrm{~d}$ & $217.17 \pm 8.87 \mathrm{a}$ \\
\hline V. vitis-idaea subsp. minus & $247.92 \pm 10.12 \mathrm{~d}$ & $34.29 \pm 1.40 \mathrm{a}, \mathrm{b}$ & $1310.87 \pm 53.52 \mathrm{a}, \mathrm{d}$ & $7074.60 \pm 288.82 \mathrm{~g}$ & $182.31 \pm 7.44 \mathrm{~d}$ & $673.22 \pm 27.48 \mathrm{~d}$ \\
\hline 'Kostromskaja rozovaja' & $2273.92 \pm 92.83 \mathrm{f}$ & $743.67 \pm 30.36 \mathrm{e}$ & $2481.71 \pm 101.32 \mathrm{e}$ & $3027.88 \pm 123.61 \mathrm{c}, \mathrm{f}$ & $486.65 \pm 19.87 \mathrm{~b}, \mathrm{c}$ & $942.07 \pm 38.46 \mathrm{f}$ \\
\hline 'Sanna' & $141.29 \pm 5.77 \mathrm{~d}$ & $60.48 \pm 2.47 \mathrm{a}, \mathrm{b}$ & $1431.05 \pm 58.42 \mathrm{~b}$ & $1364.89 \pm 55.72 \mathrm{a}$ & $442.12 \pm 18.05 \mathrm{c}$ & $184.24 \pm 7.52 \mathrm{a}$ \\
\hline 'Rubin' & $2093.02 \pm 85.45 \mathrm{~g}$ & $669.11 \pm 27.32 \mathrm{f}$ & $2525.23 \pm 103.09 \mathrm{e}$ & $3109.55 \pm 126.95 \mathrm{~d}, \mathrm{e}, \mathrm{f}$ & $175.47 \pm 7.16 \mathrm{~d}$ & $760.37 \pm 31.04 \mathrm{e}$ \\
\hline 'Kostromička' & $767.38 \pm 31.33 \mathrm{a}, \mathrm{c}$ & $33.11 \pm 1.35 \mathrm{a}, \mathrm{b}$ & $3894.92 \pm 159.01 \mathrm{f}$ & $2684.38 \pm 109.59 \mathrm{c}$ & $444.92 \pm 18.16 \mathrm{c}$ & $704.39 \pm 28.76 \mathrm{~d}, \mathrm{e}$ \\
\hline V. vitis-idaea var. leucocarpum & $1705.80 \pm 69.64 \mathrm{~h}$ & $131.83 \pm 5.38 \mathrm{~g}$ & $4645.97 \pm 189.67 \mathrm{~g}$ & $3448.43 \pm 140.78 \mathrm{~b}, \mathrm{e}$ & $954.03 \pm 38.95 \mathrm{e}$ & $1025.34 \pm 41.86 \mathrm{~g}$ \\
\hline 'Erntesegen' & $168.93 \pm 6.90 \mathrm{~d}$ & n.d. ${ }^{2}$ & $1055.40 \pm 43.09 \mathrm{c}, \mathrm{d}$ & $1365.75 \pm 55.76 \mathrm{a}$ & $243.70 \pm 9.95 \mathrm{f}$ & $218.81 \pm 8.93 \mathrm{a}$ \\
\hline 'Erntedank' & $171.29 \pm 6.99 \mathrm{~d}$ & n.d. & $936.48 \pm 38.23 \mathrm{c}$ & $476.93 \pm 19.47 \mathrm{~h}$ & $352.68 \pm 14.40 \mathrm{a}$ & $231.42 \pm 9.45 \mathrm{a}$ \\
\hline
\end{tabular}

${ }^{1}$ Contents marked without the same letters $(\mathrm{a}, \mathrm{b}, \mathrm{c}, \mathrm{d}, \mathrm{e}, \mathrm{f}, \mathrm{g}, \mathrm{h})$ in the columns indicate statistically significant differences among cultivars or lower taxa $(p<0.05) ;{ }^{2}$ n.d.-peak not detected. 
Arbutin was the most abundant phenolic compound in all tested cultivars and lower taxa (Table 1). This compound contributed approximately $41-78 \%$ of the total phenolics in different cultivars and lower taxa of lingonberries. The coefficient of variation (CV) of arbutin among tested cultivars and lower taxa was $67 \%$. Significantly the highest content of arbutin was found in 'Kostromskaja rozovaja', followed by 'Rubin' cultivar, meanwhile the lowest in 'Sanna', 'Erntedank', 'Erntesegen' cultivars of lingonberries.

Large amounts of some flavonols in the present study were found (Table 1). Significantly the highest contents of avicularin were determined in V. vitis-idaea var. leucocarpum, whereas that of hyperoside were found in $V$. vitis-idaea subsp. minus and $V$. vitis-idaea var. leucocarpum. The CV of avicularin (39\%) and hyperoside ( $47.5 \%)$ were the lowest of all detected compounds. It was determined, that quercitrin was predominant flavonol in V. vitis-idaea subsp. minus and 'Sussi', 'Koralle', 'Sanna', and 'Erntedank' cultivars of lingonberries. Amounts of astragalin were considerably lower than that of other phenolic compounds, and ranged between $3.07 \pm 0.13 \mu \mathrm{g} / \mathrm{g}$ DW in 'Masovia' and $120.60 \pm 4.92 \mu \mathrm{g} / \mathrm{g}$ DW in 'Rubin' cultivar. The sum of flavonol glycosides made up from $9 \%$ to $41 \%$ of the phenolic content in 'Kostromskaja rozovaja' and 'Koralle' cultivars, respectively.

The determined amounts of (+)-catechin and (-)-epicatechin varied within a very wide range (Table 2). The CV of these compounds was $91 \%$ and $129 \%$, respectively. The peak of (-)-epicatechin was not detected in 'Erntesegen' and 'Erntedank' cultivars. Amounts of monomeric flavanols, mentioned above, were lower than those of oligomeric proanthocyanidins. The content of procyanidin $\mathrm{C} 1$ among the tested cultivars and lower taxa ranged between $936.48 \pm 38.23$ and $4645.97 \pm 189.67 \mu \mathrm{g} / \mathrm{g}$ DW with the highest amount determined in $V$. vitis-idaea var. leucocarpum. Whereas content of procyanidin A2 varied from $476.93 \pm 19.47$ to $7074.60 \pm 288.82 \mu \mathrm{g} / \mathrm{g}$ DW with the highest amount in $V$. vitis-idaea subsp. minus. Procyanidins $\mathrm{C} 1$ and A2 contribution to V. vitis-idaea var. leucocarpum either V. vitis-idaea subsp. minus was about $16-17 \%$ of the total detected phenolics. The total content of flavanols and proanthocyanidins ranged between $1584.70 \pm 64.70 \mu \mathrm{g} / \mathrm{g}$ DW in 'Erntedank' cultivar and $9932.02 \pm 405.47 \mu \mathrm{g} / \mathrm{g}$ DW in $V$. vitis-idaea var. leucocarpum.

The sum of detected hydroxycinnamic acids made up only $1-4 \%$ of the phenolic content in different cultivars and lower taxa of lingonberries (Table 2). The CV was 55\% and 59\% for chlorogenic acid and cryptochlorogenic acid, respectively. Highest contents of chlorogenic and cryptochlorogenic acids were determined in the extracts from $V$. vitis-idaea var. leucocarpum.

Concerning the total amounts of detected phenolic compounds within the cultivars, it was determined that the greatest amounts of compounds were in the extracts from 'Rubin' and 'Kostromskaja rozovaja' cultivars, whereas the lowest ones-in 'Erntedank', 'Erntesegen', and 'Sanna' cultivars (data not shown).

\subsection{Hierarchical Cluster Analysis of Phenolic Compounds of Lingonberry Leaves of Different Cultivars and Lower Taxa}

The cluster analysis has separated investigated lingonberry cultivars and lower taxa into three statistically significant clusters (Figure 4). The lingonberry cultivars attributed of the first cluster were German cultivars-'Erntekrone', 'Erntesegen', 'Erntedank', Swedish cultivars-'Sanna' and 'Sussi', 'Koralle', 'Masovia', and V. vitis-idaea var. leucocarpum. Leave samples of this cluster were characterized by lower levels of all identified compounds and significantly the lowest arbutin and procyanidins A2 and C1 levels (13,809.08 $\mu \mathrm{g} / \mathrm{g}, 2232.95 \mu \mathrm{g} / \mathrm{g}, 1601.57 \mu \mathrm{g} / \mathrm{g} \mathrm{DW}$, respectively). The predominant compound and cluster marker was quercitrin (on the average $2916.17 \mu \mathrm{g} / \mathrm{g} \mathrm{DW}$ ). The cluster two was distinguished by the highest $(p<0.05)$ amounts of quercitrin, hyperoside and procyanidin A2 (on the average $3627.50 \mu \mathrm{g} / \mathrm{g}, 4125.29 \mu \mathrm{g} / \mathrm{g}, 4289.51 \mu \mathrm{g} / \mathrm{g}$ DW, respectively). Lingonberries of Russian ('Rubin', 'Kostromička') and Canada origin (V. vitis-idaea subsp. minus) were attributed to this cluster. The Russian origin 'Kostromskaja rozovaja' was attributed to the third cluster, which was characterized by the highest $(p<0.05)$ amounts of astragalin and procyanidin $\mathrm{C} 1(3894.92 \mu \mathrm{g} / \mathrm{g} \mathrm{DW})$ and the lowest $(p<0.05)$ amounts of $(-)$-epicatechin. 


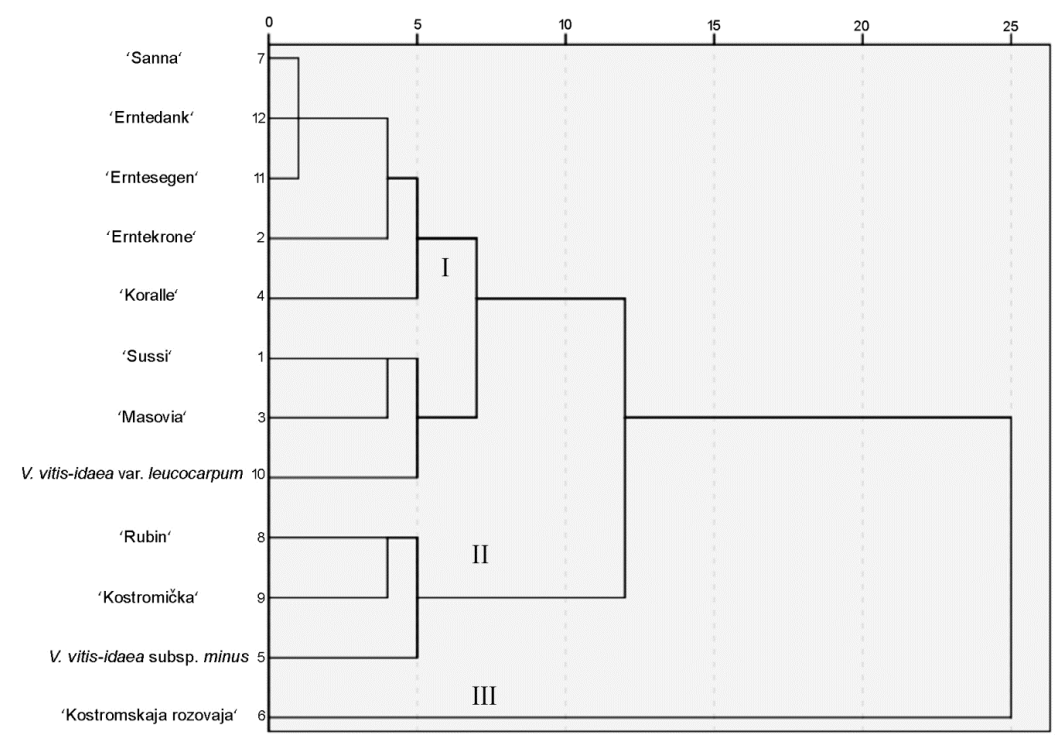

Figure 4. Dendrogram based on the amounts of phenolic compounds of lingonberry cultivars and lower taxa.

\subsection{Antioxidant Activity of Lingonberries Phenolic Compounds}

In purpose of better understanding of structure-antioxidant activity relationship, we investigated not only standards of phenolic compounds, which we detect in our study but also several compounds which were detected in lingonberry materials in previous studies. The chemical structures of phenolic compounds, that can be found in lingonberry leaves, and have been investigated in our study, are shown in Figure 5.

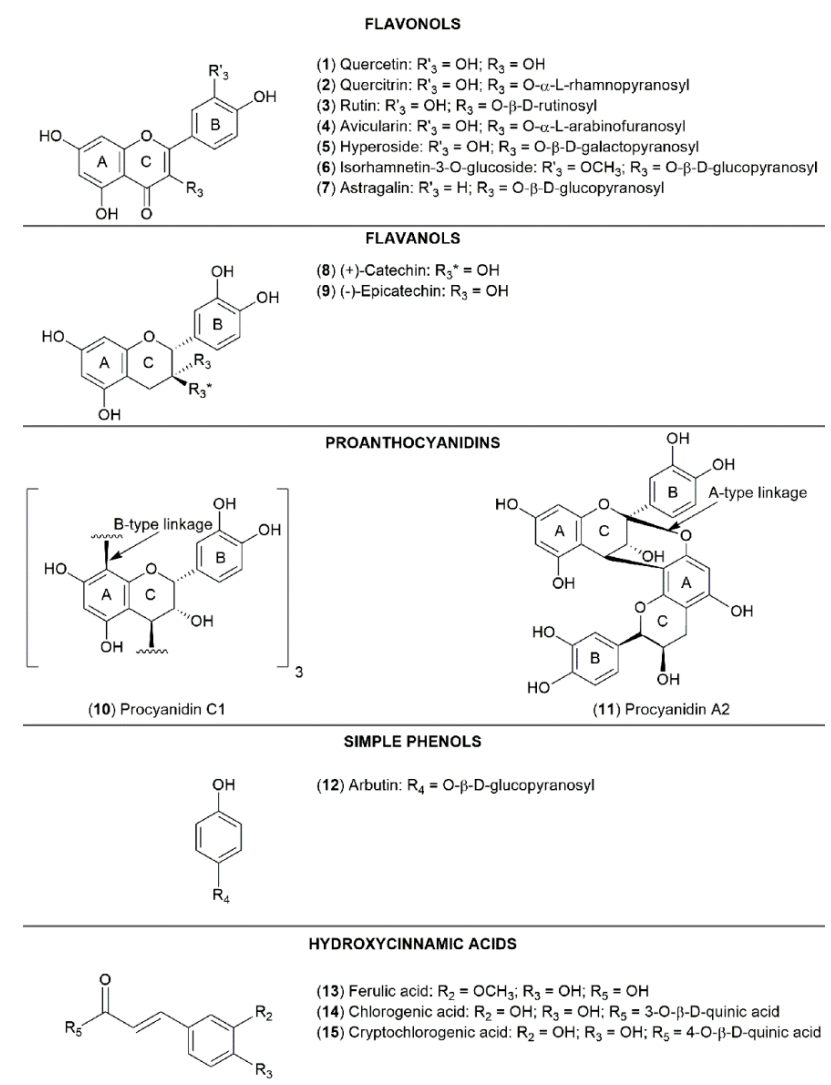

Figure 5. The chemical structures of studied phenolic compounds (1-15). 


\subsubsection{ABTS Radical Scavenging Activity}

The radical scavenging activity of tested phenolic compounds and Trolox increased with their concentration. All calibration curves equations followed a linear regression model $(p<0.05)$ (Table 3$)$.

Table 3. Calibration curves $(y=a x+b)$ data obtained by ABTS assay for tested compounds.

\begin{tabular}{cccccc}
\hline Compound & $\begin{array}{c}\text { Concentration } \\
\text { Range }(\mathbf{m M})\end{array}$ & Slope (a) & Intercept (b) & Correlation (R) & $\begin{array}{c}\text { Coefficient of } \\
\text { Determination }\left(\mathbf{R}^{\mathbf{2}}\right)\end{array}$ \\
\hline Trolox & $0.13-2.00$ & 0.3559 & +0.0580 & 0.9983 & 0.9966 \\
Quercetin & $0.10-1.66$ & 0.6709 & $-0,0028$ & 0.9968 & 0.9935 \\
Quercitrin & $0.06-0.89$ & 0.3810 & +0.0538 & 0.9986 & 0.9973 \\
Rutin & $0.05-0.82$ & 0.5378 & +0.0627 & 0.9952 & 0.9976 \\
Avicularin & $0.07-1.15$ & 0.5378 & +0.1791 & 0.9988 & 0.9977 \\
Hyperoside & $0.05-0.86$ & 0.5861 & +0.0224 & 0.9975 & 0.9981 \\
Isorhamnetin-3-O-glucoside & $0.07-1.05$ & 0.3332 & +0.0642 & 0.9986 & 0.9993 \\
Astragalin & $0.07-1.12$ & 0.4714 & +0.0989 & 0.9911 & 0.9955 \\
(+)-Catechin & $0.09-1.38$ & 0.5544 & +0.0632 & 0.9964 & 0.9929 \\
(-)-Epicatechin & $0.09-1.38$ & 0.6069 & +0.0649 & 0.9969 & 0.9938 \\
Procyanidin C1 & $0.04-0.58$ & 1.0404 & +0.9958 & 0.9958 & 0.9917 \\
Procyanidin A2 & $0.05-0.87$ & 0.7511 & +0.1408 & 0.9995 & 0.9990 \\
Arbutin & $0.11-1.84$ & 0.3392 & +0.0512 & 0.9960 & 0.9920 \\
Ferulic acid & $0.16-2.58$ & 0.2730 & +0.1183 & 0.9966 & 0.9932 \\
Chlorogenic acid & $0.09-1.41$ & 0.3038 & +0.0775 & 0.9975 & 0.9950 \\
Cryptochlorogenic acid & $0.02-0.28$ & 0.2761 & +0.0151 & 0.9969 & 0.9938 \\
\hline
\end{tabular}

The Trolox equivalent antioxidant capacity values obtained by the ABTS assay (TEAC ABTS $_{\text {) }}$ indicated how many times the radical scavenging activity of the tested phenolic compound was greater than that of Trolox (Figure 6). Significantly the greatest $\mathrm{TEAC}_{\mathrm{ABTS}}$ values were determined for proanthocyanidins-procyanidins $\mathrm{C} 1$ and A2. Their scavenging activity was $2.92 \pm 0.07$ and $2.11 \pm 0.03$ times greater than Trolox, respectively. TEAC $\mathrm{ABTS}_{\mathrm{B}}$ of monomeric flavanols was considerably lower than that of oligomeric polyphenols, mentioned above. The radical scavenging activity of (-)-epicatechin $(1.71 \pm 0.06)$ was greater than that of $(+)$-catechin $(1.56 \pm 0.02)$, and this difference was statistically significant. Among tested flavonols, quercetin was the most effective scavenger of the ABTS cation radical (1.89 \pm 0.01$)$. Glycosylation of the 3-hydroxyl in the quercetin molecule had an effect on the scavenging activity, as a result, $\mathrm{TEAC}_{\mathrm{ABTS}}$ of quercitrin, rutin, avicularin, and hyperoside was significantly inferior to quercetin. The scavenging activity of kaempferol glycoside-astragalin was lower than that of all quercetin glycosides, with the exception of quercitrin. Alkylation of catechol moiety further reduced ability to scavenge radicals, therefore $\mathrm{TEAC}_{\mathrm{ABTS}}$ of isorhamnetin-3-glucoside was lowest of all tested flavonoids $(0.94 \pm 0.05)$. Its TEAC $\mathrm{ABTS}$ was almost the same as that of glycosylated hydroquinone-arbutin $(0.95 \pm 0.02)$. The results showed, that hydroxycinnamic acids (ferulic, chlorogenic, and cryptochlorogenic acids) were less active than tested flavonoids, and despite structural differences, there was no statistically significant disparity among them. 


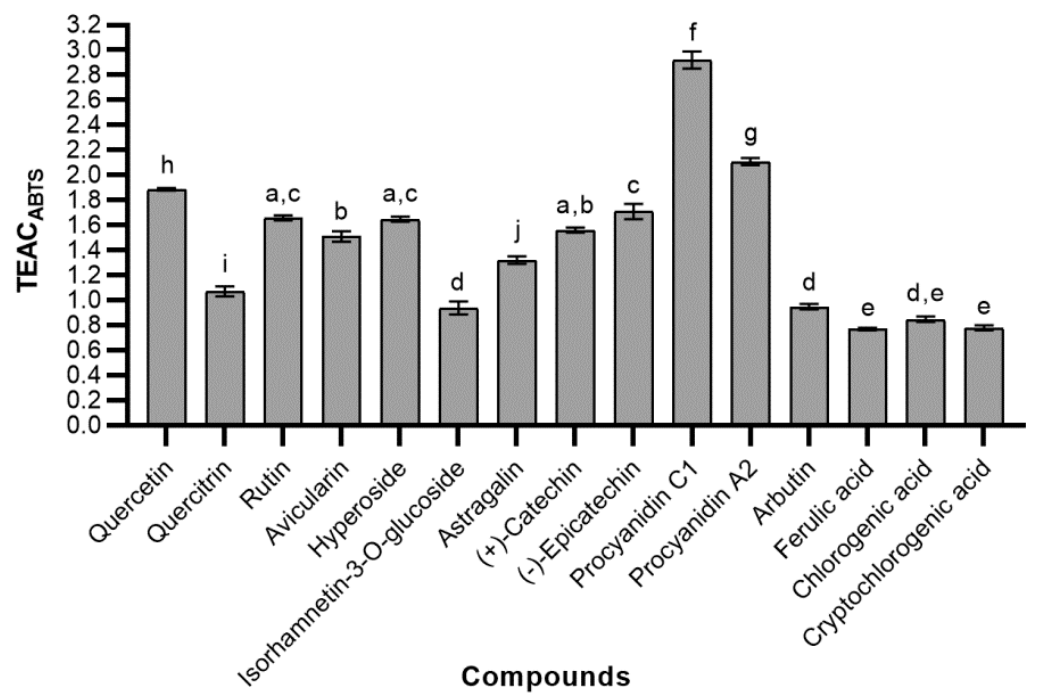

Figure 6. The radical scavenging activity of tested phenolic compounds; bars without the same letters $(a, b, c, d, e, f, g, h, i, j)$ indicate statistically significant differences between the means $(p<0.05)$.

\subsubsection{Ferric Reducing Antioxidant Power (FRAP)}

It was determined that the reducing power of tested phenolic compounds and Trolox was concentration dependent. All calibration curves equations followed a linear regression model $(p<0.05)$ (Table 4$)$.

Table 4. Calibration curves $(y=a x+b)$ data obtained by ferric reducing antioxidant power (FRAP) assay for tested compounds.

\begin{tabular}{cccccc}
\hline Compound & $\begin{array}{c}\text { Concentration } \\
\text { Range }(\mathbf{m M})\end{array}$ & Slope (a) & Intercept (b) & Correlation (R) & $\begin{array}{c}\text { Coefficient of } \\
\text { Determination }\left(\mathbf{R}^{\mathbf{2}}\right)\end{array}$ \\
\hline Trolox & $0.13-2.00$ & 0.5277 & -0.0165 & 0.9998 & 0.9997 \\
Quercetin & $0.10-1.66$ & 0.9283 & -0.0671 & 0.9996 & 0.9992 \\
Quercitrin & $0.06-0.89$ & 0.5712 & -0.0217 & 0.9975 & 0.9950 \\
Rutin & $0.05-0.82$ & 0.7531 & -0.0157 & 0.9969 & 0.9938 \\
Avicularin & $0.07-1.15$ & 0.5936 & +0.0268 & 0.9950 & 0.9900 \\
Hyperoside & $0.05-0.86$ & 0.6692 & -0.0121 & 0.9995 & 0.9989 \\
Isorhamnetin-3-O-glucoside & $0.07-1.05$ & 0.2559 & +0.0292 & 0.9951 & 0.9903 \\
Astragalin & $0.07-1.12$ & 0.3119 & -0.0231 & 0.9976 & 0,9951 \\
(+)-Catechin & $0.09-1.38$ & 0.5836 & -0.0203 & 0.9980 & 0.9960 \\
(-)-Epicatechin & $0.09-1.38$ & 0.6172 & -0.0080 & 0.9991 & 0.9981 \\
Procyanidin C1 & $0.04-0.58$ & 1.5679 & +0.0101 & 0.9999 & 0.9998 \\
Procyanidin A2 & $0.05-0.87$ & 1.0766 & -0.0248 & 0.9960 & 0.9921 \\
Arbutin & $0.11-1.84$ & 0.1826 & -0.0021 & 0.9957 & 0.9957 \\
Ferulic acid & $0.16-2.58$ & 0.3173 & +0.0708 & 0.9961 & 0.9914 \\
Chlorogenic acid & $0.09-1.41$ & 0.5937 & +0.0218 & 0.9992 & 0.9984 \\
Cryptochlorogenic acid & $0.02-0.28$ & 0.4563 & +0.0092 & 0.9972 & 0.9944 \\
\hline
\end{tabular}

The Trolox equivalent antioxidant capacity values obtained by the FRAP assay (TEAC FRAP) revealed how many times the reducing activity of the tested phenolic compound was greater than that of Trolox (Figure 7). The profile of reducing activity was similar to the results of the free radical scavenging activity. As in the ABTS assay, proanthocyanidins showed the greatest activity. TEAC $\mathrm{FRAP}_{\mathrm{P}}$ was $2.97 \pm 0.07$ and $2.04 \pm 0.04$ for procyanidins $\mathrm{C} 1$ and $\mathrm{A} 2$, respectively. These results demonstrate that proanthocyanidins have a strong potency to donate electrons to reactive free radicals, converting them into more stable forms. In this assay there was no statistically significant difference in reducing activity between different isomers of catechin. As expected, quercetin was the most active flavonoid (1.76 \pm 0.02$)$. High TEAC $C_{\text {FRAP }}$ was also observed in some quercetin glycosides-rutin (1.43 \pm 0.05$)$ and hyperoside $(1.27 \pm 0.05)$. The lowest reducing power had arbutin-its ability to reduce ferric ions was about three times lower than Trolox, and even eight and a half times lower than procyanidin C1. It was 
assessed that TEAC $\mathrm{FRAP}_{\text {was }} 0.60 \pm 0.01,1.13 \pm 0.02$, and $0,86 \pm 0.02$ for ferulic acid, chlorogenic acid, and cryptochlorogenic acid, respectively.

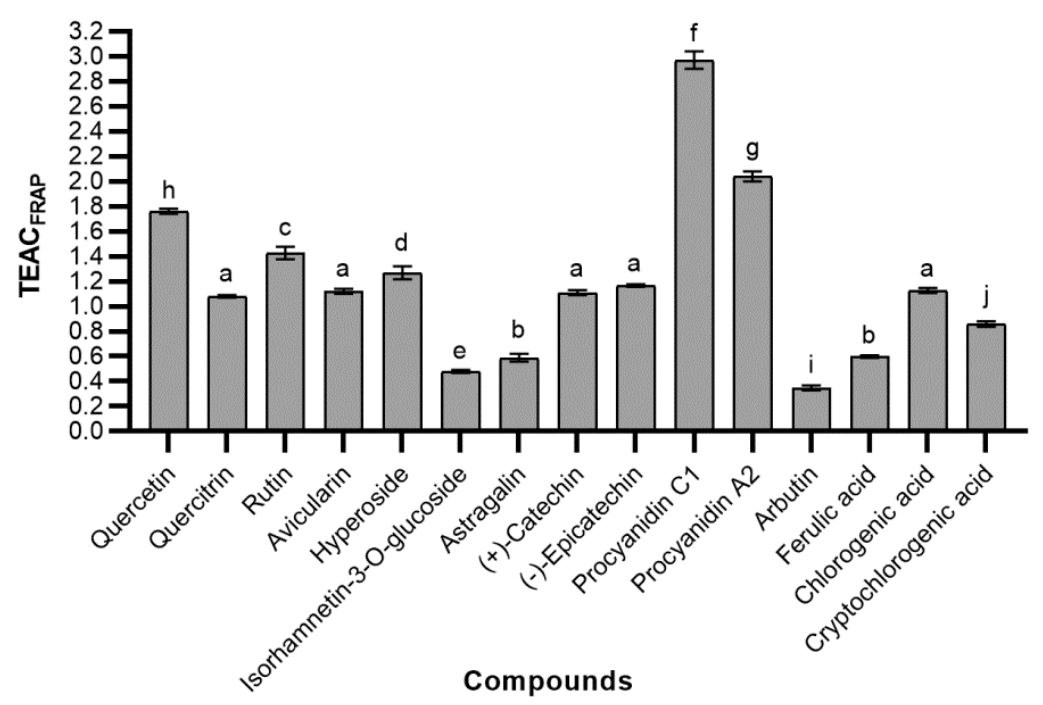

Figure 7. The reducing activity of tested phenolic compounds; bars without the same letters (a, b, c, d, $\mathrm{e}, \mathrm{f}, \mathrm{g}, \mathrm{h}, \mathrm{i}, \mathrm{j})$ indicate statistically significant differences between the means $(p<0.05)$.

\subsubsection{Ferrous Ions Chelating (FIC) Activity}

In the ferrous ions chelating assay, we did not obtain the linear concentration-response curves, because results of simple linear regression analysis showed that there was no linear relationship between concentrations of phenolic compounds (tested concentration range 5-80 $\mathrm{\mu g} / \mathrm{mL}$ ) and chelating activity ( $p>0.05$ for regression coefficients). Therefore we only investigated and compared the chelating activity of the same $20 \mu \mathrm{g} / \mathrm{mL}$ concentration of the standards of phenolic compounds. All tested phenolic compounds were able to chelate ferrous ions at this concentration, nevertheless, they possessed significantly lower chelating activity than the same concentration chelating agent-EDTA $(88.55 \pm 2.84 \%)$. The greatest ability to chelate ferrous ions was observed in quercetin followed by procyanidin C1 (62.74 $\pm 1.80 \%$ and $58.53 \pm 1.73 \%$, respectively) (Figure 8). Rutin was the most active quercetin glycoside, its chelating activity was similar to procyanidin A2 $(48.38 \pm 0.91 \%$ and $45.25 \pm 1.86 \%$, respectively). It was determined, that the type of other glycosides had no significant influence on the chelating activity. Furthermore, the chelating activity of all quercetin glycosides, except rutin, did not differ significantly from kaempferol glycoside and flavanols. The highest influence on chelating activity had methylation of catechol moiety, hence isorhamnetin-3-O-glucoside had the lowest activity of all tested compounds $(12.08 \pm 1.55 \%)$. Surprisingly, high chelating activity was determined in arbutin (33.44 $\pm 1.63 \%)$. We hypothesize that this is likely due to the specific pharmacophore and differences in reaction stoichiometry. By comparing the chelating activity of phenolic acids, a similar trend as in FRAP assay was found, with the exception, that there was no difference between the activity of chlorogenic acid isomers. 


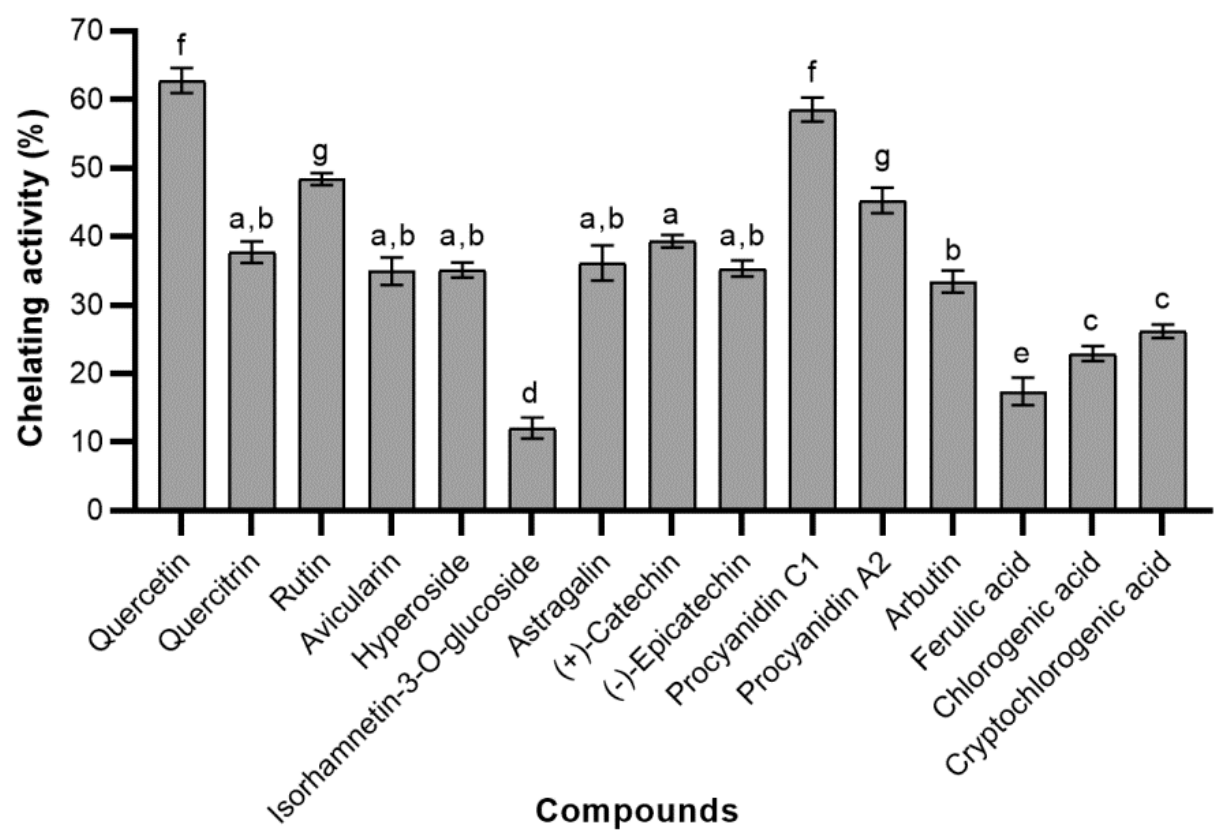

Figure 8. The chelating activity of tested phenolic compounds at a concentration of $20 \mu \mathrm{g} / \mathrm{mL}$; bars without the same letters $(a, b, c, d, e, f, g)$ indicate statistically significant differences between the means $(p<0.05)$.

\subsection{Correlation Analysis}

Antioxidant activities of lingonberry leaves extracts were correlated to the amounts of their phenolic constituents. There was a moderate positive correlation between reducing activity and the contents of cryptochlorogenic acid $(R=0.609, p<0.05)$, (-)-epicatechin $(R=0.593, p<0.05)$, arbutin $(R=0.622, p<0.05)$, and furthermore between chelating activity and the contents of cryptochlorogenic acid $(\mathrm{R}=0.665, p<0.05)$ and arbutin $(\mathrm{R}=0.621, p<0.05)$. No significant correlations were determined between antioxidant activity and contents of other tested compounds.

Correlations between methods of analysis measuring different antioxidant properties were also investigated. There was an overall strong positive correlation between FIC and FRAP assays measuring antioxidant properties in cultivars of lingonberry leaves extracts $(R=0.844, p<0.05)$. The assessed TEAC ${ }_{\text {ABTS }}$ of studied phenolic compounds were similar to TEAC $\mathrm{FRAP}_{\mathrm{P}}(\mathrm{R}=0.904, p<0.05)$. Moreover, there were a strong correlations between FIC values and $\mathrm{TEAC}_{\mathrm{ABTS}}(\mathrm{R}=0.817, p<0.05)$ either TEAC $\mathrm{FRAP}_{\mathrm{F}}(\mathrm{R}=0.766, p<0.05)$. This indicates that there is a relationship between the mechanism of action of phenolic compounds, and the same structural fragments may be responsible for different antioxidant properties.

\section{Discussion}

Phytochemical composition of lingonberry leaves strongly depends on the growing region. In our study, we have determined the quantitative and qualitative composition of bioactive compounds in lingonberries, the predominant compounds in phytochemical and antioxidant profiles, the differences in bioactive compound complexes of the distinct cultivated cultivars, subspecies, and variety.

Antioxidant properties of lingonberry leaves are in agreement with previous studies. Bujor et al. compared antioxidant activity between different parts of lingonberry, and determined that the antioxidant activity of lingonberry leaves is considerably greater than that of fruits [4]. Enkhtuya et al., investigated radical scavenging and reducing activities of different plants, and found that in DPPH, ABTS, and FRAP methods of analysis lingonberry leaves were more active than leaves of black currant, hawthorn, strawberry, and tall currant. Radical scavenging and reducing properties of lingonberry leaves were similar to that of seabuckthorn [16]. Vyas et al. found significant differences of radical scavenging and reducing activities of lingonberry leaves within wild clones and cultivars, 
and distinguished $V$. vitis-idaea subsp. minus with high antioxidant properties [7]. Tian et al. assessed that within 10 min the lingonberry leaves extracts scavenged $86.3 \pm 2.5 \%$ of DPPH radicals, and had an extremely high ORAC activity [13]. This indicates that lingonberry leaves exhibit great ability to donate hydrogen atom or transfer single-electron. Concerning chelating activity, some researchers reported that lingonberry extracts showed weaker chelating activity than extracts from plants belonging to other families [16,17]. However, it is difficult to compare the antioxidant activity results obtained in the present study with the literature data, because of the differences in methods and expression of antioxidant activity.

Based on our findings of the qualitative and quantitative analysis, arbutin was the predominant phenolic compound in all cultivars and lower taxa ranging from $7070.25 \pm 288.64 \mu \mathrm{g} / \mathrm{g}$ up to $56,968.56 \pm 2325.73 \mu \mathrm{g} / \mathrm{g}$ DW. Arbutin has been reported in previous studies to be a major phenolic constituent of lingonberry leaves [18,19]. The HPLC-PDA study of arbutin content in lingonberry leaves has given the result of $5168 \pm 480 \mu \mathrm{g} / \mathrm{g}$ DW [20], which is similar to the result obtained in 'Kostromskaja rozovaja' cultivar.

Large amounts of flavonols in lingonberries have been confirmed by several researchers. Liu et al. determined that flavonol glycosides were the second major group of phenolics in lingonberry leaves [1]. Tian et al. emphasized that amount of flavonol glycosides is one of the main difference of phenolic profile between lingonberry leaves and fruits and assessed that contents of flavonol glycosides are considerably greater in lingonberry leaves [21]. Scientific studies demonstrate that not only hyperoside, avicularin, quercitrin, and astragalin can be detected in lingonberry leaves but also quercetin aglycon, rutin, and 3-O-glycosides of quercetin, isorhamnetin, and kaempferol [18,19,21-23].

(+)-Catechin, (-)-epicatechin, proanthocyanidins, primarily as A-type or B-type procyanidin dimers and trimers, have been reported in a number of publications to be widespread in lingonberry leaves [1,13,23-26]. However, the determination of proanthocyanidins by HPLC is problematic because proanthocyanidins often occur in complexes, that makes their separation and detection difficult [22]. This suggests that there are not only procyanidins $\mathrm{C} 1$ and A2, which were detected in present material but also more types of proanthocyanidins.

Low contents of hydroxycinnamic acids obtained in our research were partly consistent with previous studies. Bujor et al. reported that hydroxycinnamic acids represent the less abundant group of phenolic compounds in the lingonberry leaves. However, they found higher levels of hydroxycinnamic acids, because the relative content of hydroxycinnamic acids and their derivatives was in the range of $6-14 \%$ in leaves [4]. The presence of caffeoylquinic acid isomers is in agreement with their detection in lingonberries in various studies $[18,23]$. Nevertheless, Tian et al. disclosed that caffeoylquinic acids were not predominant compounds in lingonberry extract [13]. Other phenolic acids in various studies were detected in the extracts of lingonberries, i.e., coumaroyl quinic acid isomers (3.81\% of the total combined peak area of all compounds), p-coumaric acid (0.64\%), caffeic acid (0.61\%), caffeoyl-shikimic acid $(0.18 \%)$, feruloyl quinic acid $(0.04 \%)$ [22], and also hexoses of ferulic acid [13], and free ferulic acid [27].

After the analysis of phytochemical and antioxidant profiles of separate lingonberry cultivars and lower taxa, there were no determined relationships with the country of origin of lingonberries nor the conditions of plants growing in trial areas. The cluster analysis revealed that according to the composition of phenolic compounds, the clusters were related to the countries of origin, especially with German and Russian origin cultivars. The predominant phenolic markers in German cultivars ('Erntekrone', 'Erntesegen', and 'Erntedank') were hyperoside and quercitrin, while in the Russian cultivars-procyanidins A2 and C1. In the study of phenolic compounds, it has been shown that in plant phylogeny and in the systematics, the composition of aglycons is a conservative feature that is very little dependent on the conditions of growth and denotes the specificity of genus and lower taxa [28]. Based on this research mentioned above, the composition of the phenolic compounds and their dominant markers are currently applied in both plant genotype studies [29], as well as antioxidant activity studies of these tribal representatives [28,30]. 
According to the results of radical scavenging, reducing and chelating activities of Lingonberries phenolic compounds, proanthocyanidins, which include in their structure epicatechin units, can be characterized by exceptionally strong antioxidant properties. These results agreed with those of Muselík et al. [31] and Spranger et al. [32], who reported that proanthocyanidins have the highest antioxidant activity among all natural phenolic compounds. This may be due to more hydroxyl groups, which act as strong hydrogen donors, generating by itself stable intramolecular hydrogen bonds with semi-quinoid free radicals and o-quinines, and thus disrupt radical chain reaction [33]. It was also found that B-type trimeric proanthocyanidins possess greater antioxidant activity than A-type dimeric proanthocyanidins.

In our study, all phenolic glycosides had lower antioxidant activity than their corresponding aglycons. It confirms that $\mathrm{O}$-glycosylation reduces the antioxidant activity of phenolic compounds [11,34,35]. It is believed that 3-O-glycosylation increases torsion angle and interferes the planarity of rings, leading to suppression of antioxidant activity [21]. Furthermore, it was noticed that in present study substitution of methoxyl group had a strong impact for reducing and chelating activities, whereas had a weaker impact for the radical scavenging activity. This suggests that the presence of electron donating methoxyl group adjacent to the hydroxyl group alters the redox potential and might enhance the hydrogen availability, donating capacity and thus radical scavenging activity [36,37]. Grzesik et al. discovered that the scavenging activity of the ABTS cation radical of ferulic acid was even greater than that of chlorogenic acid, meanwhile ability to reduce ferric ions was weaker [38].

The importance of catechol moiety (ortho-dihydroxyl structure) in the ring B was emphasized by previous studies $[9,12,34]$. In the present study, it was observed that catechol moiety increases the antioxidant activity because all quercetin glycosides still showed higher radical scavenging and reducing activities than kaempferol glycoside. Moreover, in all methods of analysis, scavenging, reducing and chelating activities of flavonol-quercetin were greater than that of flavanols-(+)-catechin and (-)-epicatechin. This can be explained by the presence of 3-hydroxy-4-keto conformation together with a 2,3-double bond in quercetin structure, which ensures extensive electron delocalization and higher stability to the aroxyl radical $[12,39]$. This structural fragment is associated particularly with a substantial ferrous ions chelation [10], consequently, quercetin can be used as a chelating standard [40]. The highest chelating activity of quercetin observed in our work supports this approach.

Determination of antioxidant activity of optical isomers showed that stereoisomery in flavanols concerning the position of the 3-hydroxyl group was not significantly important for reducing activity and ferrous ions chelation. This is in accordance with the findings reported earlier $[10,31]$.

Greater reducing and chelating activity of chlorogenic and cryptochlorogenic acid compared with that of ferulic acid indicate that esterification of phenolic acids and the additional hydroxyl group on the aromatic ring have the significant influence on the antioxidant activity. These results are consistent with those of Natella et al. [37] and Sova [41], who reported that the antioxidant activity of phenolic acids is enhanced by the introduction of a second hydroxyl group. Chen et al. proved that esters can be an even more effective than free phenolic acids, suggesting that ester functional group favorably stabilize the specific radical species, and thus enhance the radical scavenging activity [42]. In addition, results from our study revealed that the 3-hydroxyl site on the quinic acid ring is more important for reducing activity than the 4-hydroxyl site.

The majority of the tested compounds in the ABTS and FRAP assays possessed higher free radical scavenging and reducing activities than Trolox $\left(\mathrm{TEAC}_{\mathrm{ABTS}}>1\right.$ and $\mathrm{TEAC}_{\mathrm{FRAP}}>1$, respectively). Scientific studies confirm that natural phenolic compounds have similar or even greater antioxidant activity by comparison with Trolox [9,38,43]. However, all tested compounds in FIC assay had lower chelating activity than EDTA. This suggests that the chelating activity of phenolic compounds is slightly weaker than free radical scavenging and reducing activities.

The overall results of antioxidant activity of tested phenolic compounds indicate that procyanidins $\mathrm{C} 1$ and $\mathrm{A} 2$ are the major contributors to the antioxidant properties of lingonberry leaves extracts. 
This explains why extracts from 'Kostromskaja rozovaja', 'Rubin' cultivars, and V. vitis-idaea var. leucocarpum, containing the high procyanidins A2 and C1 content, possessed high reducing and chelating activities. Definitely, the antioxidant activity of the latter cultivar was predetermined by the high contents of flavonol glycosides and hydroxycinnamic acids.

Notwithstanding the fact that arbutin is more related for other biological properties, such as a diuretic, urinary antiseptic, melanin biosynthesis in human skin suppressing $[6,18,20]$, and weak radical scavenging and reducing activities were obtained in the present study, correlation analysis still showed that this compound is related to antioxidant properties of lingonberries. So we assume that extraordinarily high contents of arbutin in all tested cultivars certainly contributes to total antioxidant activity.

One of the weakest antioxidant activity of 'Erntedank' cultivar can be explained by low contents of all detected phenolics, especially by small amounts of procyanidins A2 and C1. Low amounts of phenolics were also detected in extracts of 'Erntesegen' cultivar, however, interestingly great antioxidant activity, especially radical scavenging properties, were found for this cultivar. We hypothesize that this might be due to the presence of some other compounds and non-phenolic antioxidants, such as organic acids or triterpenoids, that can be found in lingonberry leaves $[2,18,44]$. Therefore, further research of lingonberry leaves composition is required.

\section{Materials and Methods}

\subsection{Plant Materials}

The lingonberry plant material was collected in the field collection of Botanical Garden of Siauliai University ( $55^{\circ} 55^{\prime} 57^{\prime \prime} \mathrm{N}, 23^{\circ} 16^{\prime} 59^{\prime \prime}$ E. (WGS)).

1 subspecies, 1 variety and 10 cultivars of $V$. vitis-idaea were analyzed in the paper.

Subspecies (subsp.) is intraspecific taxa between species and variety (var.) and variety is intraspecific taxa between subspecies and form (f.). First cultivars of $V$. vitis-idaea were the morphotypes selected from natural habitats. Morphotype is clones of lingonberry, which differ morphologically but are not investigated genetically [3].

Characteristic of cultivars. German cultivars: 1) 'Erntekrone' (registered in 1978); 2) 'Erntesegen' (1981); 'Erntedank' (1975). All cultivars as morphotypes were selected from the natural populations. Dutch cultivar: 4) 'Koralle' (1969); Swedish cultivars: 5) 'Sanna' (1987); 6) 'Sussi' (1985). Both cultivars were registered in Denmark and selected from the seeds collected in Smaland (Sweden). Polish cultivar: 7) 'Masovia' (1985). Cultivar selected from the natural population in Lasy Bolimowskie forest $60 \mathrm{~km}$ from Warsaw. Russian cultivars: 8) 'Kostromskaja rozovaja' (1995); 9) 'Kostromička' (1995); and 10) 'Rubin' (1997). All cultivars selected from wild plants [3].

Characteristic of subspecies. V. vitis-idaea subsp. minus (Lodd.) Hult. is spread in arctic and subarctic zones of Eurasia and North America.

Characteristic of variety. V. vitis-idaea var. leucocarpum Asch. et Magnus. In 1993 the population belonging to this variety (plants with white berries) was found in the forest of Svencioneliai district, Lithuania [45]. This variety is included to The List of National Genetic Resources of Lithuania Republic.

In 2006 V. vitis-idaea subsp. minus was received as seeds from The Montreal Botanical Garden (Canada). In 2005 V. vitis-idaea var. leucocarpum and all cultivars, except 'Koralle' were received from the Institute of Botany of the Nature Research Centre (Vilnius) as clones. In 2004 clones of 'Koralle' were obtained from Vilnius University Botanical Garden.

Specimens of cultivars and lower taxa of lingonberries are deposited in the Herbarium of the Botanical Garden of Siauliai University (HUS).

Cultivation conditions. 1. The meteorological data (temperature $\left({ }^{\circ} \mathrm{C}\right.$ ); precipitation $(\mathrm{mm})$; moisture (\%) and sunshine duration (h)) were obtained from the archive of Lithuanian Hydrometeorological Service under the Ministry of Environment. Dynamics of meteorological factors are presented in Appendix A (Figure A1). 2. Plants were cultivated in a medium-sunny place, in acid 
peaty and well-drained soil. Fertilization and irrigation were applied during the season according to the meteorological situation. Plant raw material for research was collected in September 2017 and dried in $40^{\circ} \mathrm{C}$.

\subsection{Chemicals and Solvents}

Distilled water was purified using a Milli-Q system (Millipore, Bedford, MA, USA). Ethanol (96\%) was obtained from Vilniaus degtine (Vilnius, Lithuania). Anhydrous acetic acid $(99.8 \%)$, hydrochloric acid (37\%) were purchased from Sigma-Aldrich (Buchs, Switzerland). The following reagents were used: 2,2'-azino-bis(3-ethylbenzothiazoline-6-sulfonic acid) diammonium salt (ABTS), 2,4,6-Tri-(2-pyridyl)-S-triazine (TPTZ), ferric chloride hexahydrate $\left(\mathrm{FeCl}_{3} \times 6 \mathrm{H}_{2} \mathrm{O}\right)$, sodium acetate $\left(\mathrm{CH}_{3} \mathrm{COONa}\right)$, 3-(2-pyridyl)-5,6-bis-(4-phenyl-sulfonic acid)-1,2,4-triazine (Ferrozine), obtained from Sigma-Aldrich (Buchs, Switzerland); potassium persulfate $\left(\mathrm{K}_{2} \mathrm{~S}_{2} \mathrm{O}_{8}\right)$, anhydrous ferrous chloride $\left(\mathrm{FeCl}_{2}\right)$ from Alfa Aesar (Karlsruhe, Germany). The following standards were used: 6-hydroxy-2,5,7,8-tetramethylchroman-2-carboxylic acid (Trolox), ethylene diamine tetra acetic acid (EDTA), quercetin, chlorogenic acid, cryptochlorogenic acid, ferulic acid, procyanidin A2 from Sigma-Aldrich (Buchs, Switzerland); arbutin, (+)-catechin, (-)-epicatechin from Fluka (Buchs, Switzerland); hyperoside, astragalin, rutin, isorhamnetin-3-O-glucoside, quercitrin from Extrasynthese (Genay, France); procyanidin C1, avicularin from ChromaDex (Irvine, CA, USA). All the reagents and standards were of analytical grade.

\subsection{Sample Preparation}

\subsubsection{Preparation of the Lingonberry Leaves Extracts}

The lingonberry leaves extracts were prepared using $0.25 \mathrm{~g}$ of dried raw material and $25 \mathrm{~mL}$ of $60 \%$ ethanol (1:100). The samples were extracted in an ultrasonic bath (Elmasonic P, Singen, Germany) at $25{ }^{\circ} \mathrm{C}$ for $15 \mathrm{~min}$. The extracts were filtered through a $0.22 \mu \mathrm{m}$ pore size filter (Carl Roth $\mathrm{GmbH}$, Karlsruhe, Germany).

\subsubsection{Preparation of the Phenolic Compounds}

The stock solutions of phenolic compounds were prepared in $96 \%$ ethanol. For the ABTS and FRAP assays, the stock solutions were diluted to five concentrations (concentration ranges shown in Tables 3 and 4). For the FIC assay, all stock solutions were diluted to final $20 \mu \mathrm{g} / \mathrm{mL}$ concentration.

\subsection{Determination of Antioxidant Activity}

Antioxidant activity of the lingonberry leaves extracts and standards of phenolic compounds, which are most commonly found in lingonberry leaves, was analyzed by spectrophotometric ABTS, FRAP, and FIC assays.

\subsubsection{ABTS Radical Cation Decolorization Assay}

The radical scavenging activity was evaluated by the scavenging of ABTS radical cation as described by Re et al. with some modifications [46]. ABTS aqueous solution was mixed with $\mathrm{K}_{2} \mathrm{~S}_{2} \mathrm{O}_{8}$ to obtain a concentration of $2 \mathrm{mM}$. The stock solution was left for $16 \mathrm{~h}$ in the dark at room temperature. The working solution was then prepared by diluting the stock solution with water to obtain an absorbance of 1.0 at $734 \mathrm{~nm}$ against the blank (water). A volume of $20 \mu \mathrm{L}$ of each extract (diluted 20 fold) or phenolic compound (at various concentration) was mixed with $3 \mathrm{~mL}$ of ABTS working solution. After $1 \mathrm{~h}$, the decrease of absorbance was measured at $734 \mathrm{~nm}$. 
ABTS radical cation scavenging activity of extracts was expressed as antioxidant Trolox equivalents (TE) per gram of material. Calculated as follows:

$$
\mathrm{TE}_{\mathrm{ABTS}}=\frac{\mathrm{c} \times \mathrm{V}}{\mathrm{m}}, \mathrm{mg} / \mathrm{g} \mathrm{DW}
$$

where: $\mathrm{c}$-Trolox concentration in $\mathrm{mg} / \mathrm{mL}$ from the calibration curve; $\mathrm{V}$ - the volume in $\mathrm{mL}$; $\mathrm{m}$ - the exact weight of the dry material, $\mathrm{g}$.

The obtained absorption decrease of five different concentrations of tested phenolic compounds and Trolox were used to construct calibration curves (Table 3). Scavenging activity of the tested

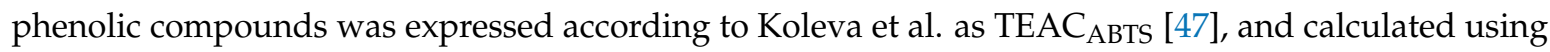
the following equation:

$$
\mathrm{TEAC}_{\mathrm{ABTS}}=\frac{\mathrm{a}_{\text {sample }}}{\mathrm{a}_{\text {trolox }}}
$$

where: $a_{\text {sample }}$-the slope of the sample obtained from the calibration curve by the ABTS assay; $\mathrm{a}_{\text {trolox }}$ - the slope of Trolox obtained from the calibration curve by the ABTS assay.

\subsubsection{Ferric Reducing Antioxidant Power (FRAP) Assay}

The ability to reduce ferric ions was measured using a modified version of the method described by Benzie and Strain [48]. Briefly, $20 \mu \mathrm{L}$ of each extract (diluted 20 folds) or phenolic compound (at various concentration) was added to $3 \mathrm{~mL}$ of freshly prepared working FRAP reagent consisted of a 10:1:1 ratio of solutions: $300 \mathrm{mM}$ of acetate buffer (pH 3.6), $10 \mathrm{mM}$ TPTZ dissolved in $40 \mathrm{mM} \mathrm{HCl}$, and $20 \mathrm{mM} \mathrm{FeCl}_{3} \times 6 \mathrm{H}_{2} \mathrm{O}$. The absorbance of the mixture was measured at 593 after $1 \mathrm{~h}$ incubation at room temperature. The sample substituted by solvent was used as a blank.

Ability to reduce ferric ions by the extracts was expressed as antioxidant Trolox equivalents (TE) per gram of material. Calculated as follows:

$$
\mathrm{TE}_{\mathrm{FRAP}}=\frac{\mathrm{c} \times \mathrm{V}}{\mathrm{m}}, \mathrm{mg} / \mathrm{g} \mathrm{DW}
$$

where: $\mathrm{c}$-Trolox concentration in $\mathrm{mg} / \mathrm{mL}$ from the calibration curve; $\mathrm{V}$ - the volume in $\mathrm{mL} ; \mathrm{m}$ - the exact weight of the dry material, g.

The obtained absorption of five different concentrations of tested phenolic compounds and Trolox were used to construct calibration curves (Table 4). Reducing activity of the tested phenolic compounds

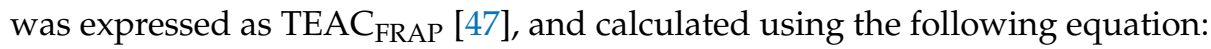

$$
\mathrm{TEAC}_{\mathrm{FRAP}}=\frac{\mathrm{a}_{\text {sample }}}{\mathrm{a}_{\text {trolox }}}
$$

where: $a_{\text {sample }}$-the slope of the sample obtained from the calibration curve by the FRAP assay; $\mathrm{a}_{\text {trolox }}$ - the slope of Trolox obtained from the calibration curve by the FRAP assay.

\subsubsection{Ferrous Ions Chelating (FIC) Activity Assay}

The chelation of ferrous ions was evaluated by the method according to Ye et al. [49], Zengin and Aktumsek [50] with slight modification. A volume of $1 \mathrm{~mL}$ of sample solution (extract diluted 3 fold or $20 \mu \mathrm{g} / \mathrm{mL}$ of the phenolic compound) was mixed with $50 \mu \mathrm{L}$ of $2 \mathrm{mM} \mathrm{FeCl}_{2}$ solution. After $5 \mathrm{~min}$, the reaction was initiated by the addition of $0.2 \mathrm{~mL}$ of $5 \mathrm{mM}$ ferrozine solution. The mixture was shaken and allowed to react at room temperature for $10 \mathrm{~min}$. The absorbance of the solution was thereafter measured at $562 \mathrm{~nm}$ against the blank. To correct for background absorbance, a blank was prepared for each measurement by replacing ferrozine to solvent. The sample substituted by solvent was used as a negative control, and strong chelating agent-EDTA in a range $0-320 \mu \mathrm{g} / \mathrm{mL}$ was 
used as a positive control. The ability of the sample to chelate ferrous ions was calculated using the following equation:

$$
\text { Ferrous ions chelating activity }(\%)=\left(1-\frac{\mathrm{As}}{\mathrm{Ac}}\right) \times 100 \%
$$

where: $A_{s}$-absorbance in the presence of the sample; $A_{c}$-absorbance of negative control.

\subsection{Qualitative and Quantitative Analysis by HPLC-PDA Method}

HPLC analysis was performed using a "Waters e2695 Alliance system" (Waters, Milford, MA, USA) with a photodiode array detector "Waters 2998" according to the HPLC-PDA method for phenolic compounds reported by Raudone et al. [51]. Briefly, the"ACE"(ACT, UK) column $(\mathrm{C} 18,150 \mathrm{~mm} \times 4.6 \mathrm{~mm}$, particle size $3 \mu \mathrm{m})$ column was used. The gradient consisted of eluent A (0.05\% trifluoracetic acid) and B (acetonitrile) and followed: $0-5$ min- $12 \%$ B, 5-50 min-12-30\% B, 50-51 $\mathrm{min}-30-90 \% \mathrm{~B}, 51-56 \mathrm{~min}-90 \% \mathrm{~B}$, and $57 \mathrm{~min}-12 \% \mathrm{~B}$ with the flow rate- $0.5 \mathrm{~mL} / \mathrm{min}$ and injection volume-10 $\mathrm{LL}$. The analyte and reference compound retention time and UV absorption spectra were used for peak identification.

\subsection{Statistical Analysis}

Statistical analysis was performed using SPSS 21.0 (SPSS Inc., Chicago, IL, USA) and Microsoft Office Excel 2010 (Microsoft, Redmond, WA, USA). All measurements were made in triplicate, and results were expressed as mean \pm standard deviation (SD). Simple linear regression analysis was performed to calculate the concentration-response relationship of each investigated compound by ABTS, FRAP and FIC assays. Correlations were tested by using the Pearson correlation test. The hierarchical cluster analysis using Euclidean distances was performed. One-way analysis of variance was performed by ANOVA test. Significant differences between means were determined by Tukey HSD multiple comparison test. The $p$-values less than 0.05 were considered statistically significant.

\section{Conclusions}

Lingonberry leaves could be a promising source of bioactive compounds with notable antioxidant activity. The determined fingerprint profiles are important tools to prove the authenticity of lingonberry products. Therefore, the identification of secondary metabolites could be very important in chemotaxonomical and phytogeographical aspect. 'Kostromskaja rozovaja', 'Rubin' cultivars and $V$. vitis-idaea var. leucocarpum, possessed the greatest reducing, radical scavenging and chelating activities. Procyanidins A2 and C1 could be proposed as markers of radical scavenging, reducing and chelating activities of lingonberries.

Author Contributions: Conceptualization, L.R.; methodology, R.R.; investigation G.V., L.P.; resources R.V., V.M.; data curation G.V., L.R.; writing-original draft preparation G.V., L.P., R.V., V.M.; writing一review and editing, L.R., V.M.; supervision, L.R.

Funding: This research received no external funding.

Conflicts of Interest: The authors declare no conflict of interest. 


\section{Appendix A}

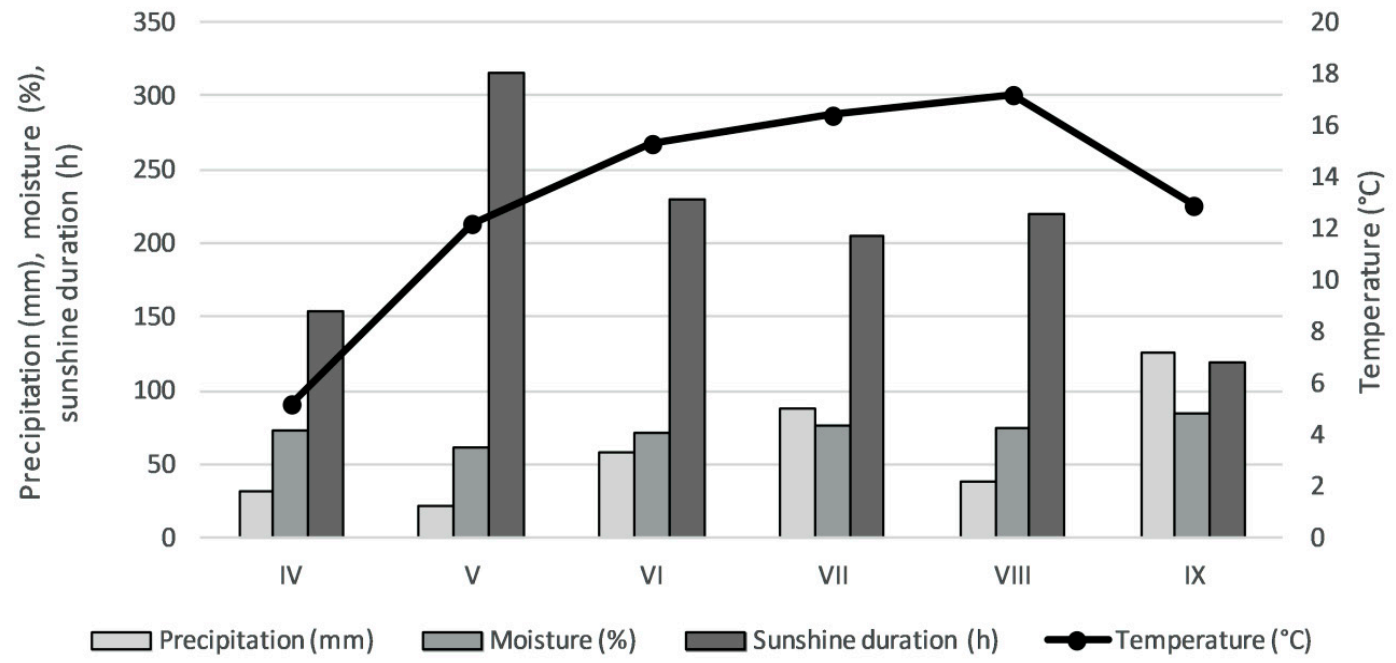

Figure A1. Cultivation conditions of tested lingonberries (dynamics of meteorological factors).

\section{References}

1. Liu, P.; Lindstedt, A.; Markkinen, N.; Sinkkonen, J.; Suomela, J.; Yang, B. Characterization Of Metabolite Profiles Of Leaves Of Bilberry (Vaccinium myrtillus L.) And Lingonberry (Vaccinium vitis-idaea L.). J. Agric. Food Chem. 2014, 62, 12015-12026. [CrossRef] [PubMed]

2. Szakiel, A.; Paczkowski, C.; Koivuniemi, H.; Huttunen, S. Comparison Of The Triterpenoid Content Of Berries And Leaves Of Lingonberry Vaccinium vitis-idaea From Finland And Poland. J. Agric. Food Chem. 2012, 60, 4994-5002. [CrossRef] [PubMed]

3. Bandzaitienè, Z.; Daubaras, R.; Labokas, J. Bruknè: Vaccinium vitis-idaea L.; Botanikos Instituto Leidykla: Vilnius, Lithuania, 2007; pp. 1323-1333.

4. Bujor, O.; Ginies, C.; Popa, V.; Dufour, C. Phenolic Compounds And Antioxidant Activity Of Lingonberry (Vaccinium vitis-idaea L.) Leaf, Stem And Fruit At Different Harvest Periods. Food Chem. 2018, 252, 356-365. [CrossRef] [PubMed]

5. Debnath, S.; McRae, K. In Vitro Culture Of Lingonberry (Vaccinium vitis-idaea L.). Small Fruits Rev. 2001, 1, 3-19. [CrossRef]

6. Ferlemi, A.; Lamari, F. Berry Leaves: An Alternative Source Of Bioactive Natural Products Of Nutritional And Medicinal Value. Antioxidants 2016, 5, 17. [CrossRef] [PubMed]

7. Vyas, P.; Curran, N.; Igamberdiev, A.; Debnath, S. Antioxidant Properties Of Lingonberry (Vaccinium vitis-idaea L.) Leaves Within A Set Of Wild Clones And Cultivars. Can. J. Plant. Sci. 2015, 95, 663-669. [CrossRef]

8. Ali, H.; Abo-Shady, A.; Sharaf Eldeen, H.; Soror, H.; Shousha, W.; Abdel-Barry, O.; Saleh, A. Structural Features, Kinetics And SAR Study Of Radical Scavenging And Antioxidant Activities Of Phenolic And Anilinic Compounds. Chem. Cent. J. 2013, 7. [CrossRef] [PubMed]

9. Csepregi, K.; Neugart, S.; Schreiner, M.; Hideg, É. Comparative Evaluation Of Total Antioxidant Capacities Of Plant Polyphenols. Molecules 2016, 21, 208. [CrossRef] [PubMed]

10. Mladěnka, P.; Macáková, K.; Filipský, T.; Zatloukalová, L.; Jahodář, L.; Bovicelli, P.; Silvestri, I.; Hrdina, R.; Saso, L. In Vitro Analysis Of Iron Chelating Activity Of Flavonoids. J. Inorg. Biochem. 2011, 105, 693-701. [CrossRef] [PubMed]

11. Wang, T.; Li, Q.; Bi, K. Bioactive Flavonoids In Medicinal Plants: Structure, Activity And Biological Fate. Asian J. Pharm. Sci. 2018, 13, 12-23. [CrossRef]

12. Lago, J.; Toledo-Arruda, A.; Mernak, M.; Barrosa, K.; Martins, M.; Tibério, I.; Prado, C. Structure-Activity Association Of Flavonoids In Lung Diseases. Molecules 2014, 19, 3570-3595. [CrossRef] [PubMed] 
13. Tian, X.; Schaich, K. Effects of Molecular Structure on Kinetics And Dynamics of the Trolox Equivalent Antioxidant Capacity Assay with ABTS+•. J. Agric. Food Chem. 2013, 61, 5511-5519. [CrossRef] [PubMed]

14. Cheynier, V.; Comte, G.; Davies, K.; Lattanzio, V.; Martens, S. Plant Phenolics: Recent Advances On Their Biosynthesis, Genetics, And Ecophysiology. Plant Physiol. Biochem. 2013, 72, 1-20. [CrossRef] [PubMed]

15. Lee, J. Establishing A Case For Improved Food Phenolic Analysis. Food Sci. Nutr. 2013, 2, 1-8. [CrossRef] [PubMed]

16. Enkhtuya, E.; Kashiwagi, T.; Shimamura, T.; Ukeda, H.; Tseye-Oidov, O. Screening Study On Antioxidant Activity Of Plants Grown Wildly In Mongolia. Food Sci. Technol. Res. 2014, 20, 891-897. [CrossRef]

17. Samoilova, Z.; Muzyka, N.; Lepekhina, E.; Oktyabrsky, O.; Smirnova, G. Medicinal Plant Extracts Can Variously Modify Biofilm Formation In Escherichia Coli. Anton. Leeuw. 2014, 105, 709-722. [CrossRef] [PubMed]

18. Ieri, F.; Martini, S.; Innocenti, M.; Mulinacci, N. Phenolic Distribution in Liquid Preparations of Vaccinium myrtillus L. and Vaccinium vitis idaea L. Phytochem. Anal. 2013, 24, 467-475. [CrossRef] [PubMed]

19. Saario, M.; Koivusalo, S.; Laakso, I.; Autio, J. Allelopathic Potential Of Lingonberry (Vaccinium vitis-idaea L.) Litter For Weed Control. Biol. Agric. Hortic. 2002, 20, 11-28. [CrossRef]

20. Rychlinska, I.; Nowak, S. Quantitative Determination Of Arbutin And Hydroquinone in Different Plant Materials By HPLC. Not. Bot. Horti Agrobot. Cluj-Napoca 2012, 40, 109-113. [CrossRef]

21. Tian, Y.; Puganen, A.; Alakomi, H.; Uusitupa, A.; Saarela, M.; Yang, B. Antioxidative And Antibacterial Activities Of Aqueous Ethanol Extracts Of Berries, Leaves, And Branches Of Berry Plants. Food Res. Int. 2018, 106, 291-303. [CrossRef] [PubMed]

22. Hokkanen, J.; Mattila, S.; Jaakola, L.; Pirttilä, A.; Tolonen, A. Identification Of Phenolic Compounds From Lingonberry (Vaccinium vitis-idaea L.), Bilberry (Vaccinium myrtillus L.) And Hybrid Bilberry (Vaccinium X Intermediumruthe L.) Leaves. J. Agric. Food Chem. 2009, 57, 9437-9447. [CrossRef] [PubMed]

23. Wojnicz, D.; Kucharska, A.; Sokół-Łętowska, A.; Kicia, M.; Tichaczek-Goska, D. Medicinal Plants Extracts Affect Virulence Factors Expression And Biofilm Formation By The Uropathogenic Escherichia coli. Urol. Res. 2012, 40, 683-697. [CrossRef] [PubMed]

24. Ek, S.; Kartimo, H.; Mattila, S.; Tolonen, A. Characterization Of Phenolic Compounds From Lingonberry (Vaccinium vitis-idaea). J. Agric. Food Chem. 2006, 54, 9834-9842. [CrossRef] [PubMed]

25. Jungfer, E.; Zimmermann, B.; Ruttkat, A.; Galensa, R. Comparing Procyanidins In Selected Vaccinium Species By UHPLC-MS2 With Regard To Authenticity And Health Effects. J. Agric. Food Chem. 2012, 60, 9688-9696. [CrossRef] [PubMed]

26. Kylli, P.; Nohynek, L.; Puupponen-Pimiä, R.; Westerlund-Wikström, B.; Leppänen, T.; Welling, J.; Moilanen, E.; Heinonen, M. Lingonberry (Vaccinium vitis-idaea) And European Cranberry (Vaccinium Microcarpon) Proanthocyanidins: Isolation, Identification, And Bioactivities. J. Agric. Food Chem. 2011, 59, 3373-3384. [CrossRef] [PubMed]

27. Okhrimenko, L.P.; Kalinkina, G.I.; Luksha, Y.I.; Kolomiytec, N.E. Study Of Phenolic Compounds Of Blueberry, Lingonberry, Bearberry, Bilberry And Wintergreen Leaves Growing In The Republic Of Sakha (Yakutia). Khimiia Rastitel'nogo Syr'ia 2009, 3, 109-115. (In Russian)

28. Vysochina, G.I. Phenolic compounds in systematics and phylogeny of the family Polygonaceae Juss. Turczaninowia 2014, 17, 33-41. (In Russian) [CrossRef]

29. Karpova, E.; Lapteva, N. Phenolic Compounds in Taxonomy of The Genus Spiraea L. Turczaninowia 2014, 17, 42-56. [CrossRef]

30. Kostikova, V.; Shaldaeva, T. The Antioxidant Activity of the Russian Far East Representatives of the Spiraea L. (Rosaceae Juss.) Genus. Russ. J. Bioorg. Chem. 2017, 43, 790-794. [CrossRef]

31. Muselík, J.; García-Alonso, M.; Martín-López, M.; Žemlička, M.; Rivas-Gonzalo, J. Measurement Of Antioxidant Activity Of Wine Catechins, Procyanidins, Anthocyanins And Pyranoanthocyanins. Int. J. Mol. Sci. 2007, 8, 797-809. [CrossRef]

32. Spranger, I.; Sun, B.; Mateus, A.; Freitas, V.; Ricardo-da-Silva, J. Chemical Characterization And Antioxidant Activities Of Oligomeric And Polymeric Procyanidin Fractions From Grape Seeds. Food Chem. 2008, 108, 519-532. [CrossRef] [PubMed]

33. Ni, L.; Zhao, F.; Li, B.; Wei, T.; Guan, H.; Ren, S. Antioxidant And Fluorescence Properties Of Hydrogenolyzised Polymeric Proanthocyanidins Prepared Using SO42- / Zro2 Solid Superacids Catalyst. Molecules 2018, 23, 2445. [CrossRef] [PubMed] 
34. Lin, C.; Zhu, C.; Hu, M.; Wu, A.; Zerendawa, B.; Suolangqimei, K. Structure-Activity Relationships Of Antioxidant Activity In Vitro About Flavonoids Isolated From Pyrethrum tatsienense. J Intercult Ethnopharmacol. 2014, 3, 123-127. [CrossRef] [PubMed]

35. Li, K.; Fan, H.; Yin, P.; Yang, L.; Xue, Q.; Li, X.; Sun, L.; Liu, Y. Structure-Activity Relationship Of Eight High Content Flavonoids Analyzed With A Preliminary Assign-Score Method And Their Contribution To Antioxidant Ability Of Flavonoids-Rich Extract From Scutellaria baicalensis Shoots. Arab. J. Chem. 2018, 11, 159-170. [CrossRef]

36. Cai, Y.; Sun, M.; Xing, J.; Luo, Q.; Corke, H. Structure-Radical Scavenging Activity Relationships Of Phenolic Compounds From Traditional Chinese Medicinal Plants. Life Sci. 2006, 78, 2872-2888. [CrossRef] [PubMed]

37. Natella, F.; Nardini, M.; Di Felice, M.; Scaccini, C. Benzoic And Cinnamic Acid Derivatives As Antioxidants: Structure-Activity Relation. J. Agric. Food Chem. 1999, 47, 1453-1459. [CrossRef] [PubMed]

38. Grzesik, M.; Naparło, K.; Bartosz, G.; Sadowska-Bartosz, I. Antioxidant Properties Of Catechins: Comparison With Other Antioxidants. Food Chem. 2018, 241, 480-492. [CrossRef] [PubMed]

39. Yordi, E.; Pérez, E.; Villares, E.; Matos, M. Antioxidant And Pro-Oxidant Effects Of Polyphenolic Compounds And Structure-Activity Relationship Evidence. In Nutrition, Well-Being and Health, 1st ed.; Bouayed, J., Ed.; InTech Open Access Publisher: Rijeka, Croatia, 2012; pp. 23-48.

40. Končić, M.; Barbarić, M.; Perković, I.; Zorc, B. Antiradical, Chelating And Antioxidant Activities Of Hydroxamic Acids And Hydroxyureas. Molecules 2011, 16, 6232-6242. [CrossRef] [PubMed]

41. Sova, M. Antioxidant And Antimicrobial Activities Of Cinnamic Acid Derivatives. Mini Rev. Med. Chem. 2012, 12, 749-767. [CrossRef] [PubMed]

42. Chen, Y.; Xiao, H.; Zheng, J.; Liang, G. Structure-Thermodynamics-Antioxidant Activity Relationships Of Selected Natural Phenolic Acids And Derivatives: An Experimental And Theoretical Evaluation. PLoS ONE 2015, 10. [CrossRef] [PubMed]

43. Di Majo, D.; La Neve, L.; La Guardia, M.; Casuccio, A.; Giammanco, M. The Influence Of Two Different $\mathrm{Ph}$ Levels On The Antioxidant Properties Of Flavonols, Flavan-3-Ols, Phenolic Acids And Aldehyde Compounds Analysed In Synthetic Wine And In A Phosphate Buffer. J. Food Compost Anal. 2011, 24, 265-269. [CrossRef]

44. Szakiel, A.; Morczek, A. Distribution Of Triterpene Acids And Their Derivatives In Organs Of Cowberry (Vaccinium vitis-idaea L.) Plant. Acta Biochim. Pol. 2007, 54, 733-740. [PubMed]

45. Bandzaitienè, Z. Bruknès (Vaccinium vitis-idaea var. leucocarpum Asch. et Magnus) baltauogis varietetas Lietuvoje. In Lietuvos Bioı̨vairovè (Būklè, Struktūra, Apsauga); Lietuvos Edukologijos Universiteto Leidykla: Vilnius, Lithuania, 1997; pp. 28-29.

46. Re, R.; Pellegrini, N.; Proteggente, A.; Pannala, A.; Yang, M.; Rice-Evans, C. Antioxidant Activity Applying An Improved ABTS Radical Cation Decolorization Assay. Free Radic. Biol. Med. 1999, 26, 1231-1237. [CrossRef]

47. Koleva, I.; Niederländer, H.; van Beek, T. Application Of ABTS Radical Cation For Selective On-Line Detection Of Radical Scavengers In HPLC Eluates. Anal. Chem. 2001, 73, 3373-3381. [CrossRef] [PubMed]

48. Benzie, I.; Strain, J. The Ferric Reducing Ability Of Plasma (FRAP) As A Measure Of "Antioxidant Power": The FRAP Assay. Anal. Biochem. 1996, 239, 70-76. [CrossRef] [PubMed]

49. Ye, H.; Zhou, C.; Sun, Y.; Zhang, X.; Liu, J.; Hu, Q.; Zeng, X. Antioxidant Activities In Vitro Of Ethanol Extract From Brown Seaweed Sargassum pallidum. Eur. Food Res. Technol. 2009, 230, 101-109. [CrossRef]

50. Zengin, G.; Aktumsek, A. Investigation Of Antioxidant Potentials Of Solvent Extracts From Different Anatomical Parts Of Asphodeline Anatolica E. Tuzlaci: An Endemic Plant To Turkey. Afr. J. Tradit. Complement. Altern. Med. 2014, 11, 481-488. [CrossRef] [PubMed]

51. Raudone, L.; Zymone, K.; Raudonis, R.; Vainoriene, R.; Motiekaityte, V.; Janulis, V. Phenological changes in triterpenic and phenolic composition of Thymus L. species. Ind. Crops Prod. 2017, 109, 445-451. [CrossRef]

Sample Availability: Samples of the compounds are available from the authors. 